\title{
ANALYSIS OF ELECTRON TRANSPORT IN THE PLASMA OF THERMIONIC CONVERTERS
}

BY

M. L. STOENESCU AND P. H. HEINICKE

\section{MASTER}

\section{PLASMA PHYSICS LABORATORY}

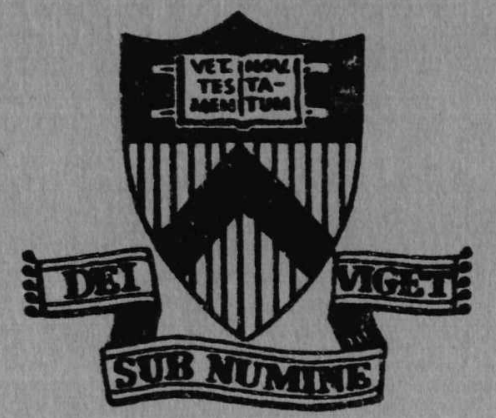

\section{PRINCETON UNIVERSITY PRINCETON, NEW JERSEY}

This work was supported by the U. S. Department of Energy Contract No. EY-76-C-02-3073. Reproduction, translation, publication, use and disposal, in whole or in part, by or for the United States Government is permitted. 


\section{DISCLAIMER}

This report was prepared as an account of work sponsored by an agency of the United States Government. Neither the United States Government nor any agency Thereof, nor any of their employees, makes any warranty, express or implied, or assumes any legal liability or responsibility for the accuracy, completeness, or usefulness of any information, apparatus, product, or process disclosed, or represents that its use would not infringe privately owned rights. Reference herein to any specific commercial product, process, or service by trade name, trademark, manufacturer, or otherwise does not necessarily constitute or imply its endorsement, recommendation, or favoring by the United States Government or any agency thereof. The views and opinions of authors expressed herein do not necessarily state or reflect those of the United States Government or any agency thereof. 


\section{DISCLAIMER}

Portions of this document may be illegible in electronic image products. Images are produced from the best available original document. 


\section{NOTICE}

This report was prepared as an account of work sponsored by the United States Government. Neither the United States nor the United States Energy Research and Development Administration, nor any of their employees, nor any of their contractors, subcontractors, or their employees, makes any warranty, express or implied, or assumes any legal liability or responsibility for the accuracy, completeness or usefulness of any information, apparatus, product or frocess disclosed, or represents that its use would not infringe privately owned rights.

Printed in the United States of America. Available from

Natioral Technical Information Service

U. S. Departinent of Commerce 5285 Port Royal Road

Sprirgfield, virginia 22151

Price: Printed Copy $\$ \ldots$; Microfiche $\$ 3.00$

*Pages

$$
1-50
$$

$51-150$

$151-325$

$326-500$

$501-1000$
NTIS

Selling Price

$\$ 4.00$

5.45

7.60

10.60

13.60 
Analysis of Electron Transport in the Plasma of Thermionic Converters

Maria L. Stoenescu and Peter H. Heinicke

Plasma Physics Laboratory, Princeton University

Princeton, New Jersey 08544

\section{ABSTRACT}

Electron transport coefficients of a gaseous ensemble are expressed analytically as function of density, and are expressed analytically as function of temperature up to an unknown function $\hat{\hat{\delta}}_{\mathrm{e}, \text { eo }}$ which has to be evaluated for each specific electron - neutral atom cross section. In order to complete the analytical temperature dependence one may introduce a polynomial expansion of the function $\hat{\hat{\delta}}_{\mathrm{e}, \mathrm{eo}}$, or, one may derive the temperature dependence of a set of coefficients, numbering thirteen for a third approximation transport evaluation, which completely determine the transport coefficients. The latter approach is used for determining the electron transport coefficients of a cesium plasma for any ion neutral composition and any temperature between $500^{\circ} \mathrm{K}$ and $3500^{\circ} \mathrm{K}$. The relation between the transport coefficients of a fully and partly ionized gas is readily available and shows that, in the classical formalism, electron-ion and electron-neutral resistivities are not additive. The present form of the transport coefficients makes possible an accurate numerical integration of transport equations eliminating lengthy computations which are frequently inaccessible. It thus provides a detailed knowledge of spatial distribution of particle and energy transport and makes possible the determination of one of the three internal voltage drops, surface barrier, sheath and plasma, which are linked together experimentally by current density versus voltage characteristics of thermionic converters. 


\section{INTRODUCTION}

The advantage of introducing cesium vapor in the thermionic converter which improves the thermionic emission by lowering the emitter work function is counteracted by the increase of plasma resistance due to the presence of neutral particles.

Optimization studies of current density at given interelectrode electric potential difference based on variation of geometrical factors, additional electrodes, additional ion sources, etc., require a complete and flexible analytical model which can produce adequate information for theory experiment correlation analysis.

The current analytical description of the thermionic converter behavior is based on the numerical solution of the transport equations in the plasma region, on simple model extrapolation of the plasma parameters through the sheath and on Poisson's equation solution for the electrostatic potential in the sheath. The solution of the transport equations is determined by the boundary conditions at the plasma-sheath interface and by the transport coefficients, which reflect local processes. These transport coefficients are calculated solving Boltzmann equation for a specific form of the velocity distribution function assumed to be a perturbed Maxwellian where the perturbation is linear in the gradients of the macroscopic variables, as introduced by Enskog 1 and Chapman and Cowling ${ }^{2}$ and presented in detail by Hirschfelder. ${ }^{3}$

In the following two paragraphs a parametric representation of the transport coefficients versus density and temperature, for a given electron-cesium atom elastic cross section is provided. A similar representation, for a hard sphere cross section, was offered by Wilkins and Gyftopoulos. ${ }^{4}$ The present formulation makes possible a numerical integration of the transport equations, for realistic cross sections, updating the transport coefficients in space and time with local values of the density and temperature.

In paragraph 4 an analysis of the electron transport in the plasma of a thermionic converter and of the plasma resistance as a result of electron neutral atom and electron-ion interactions, for typical converter conditions, is presented. 
The last paragraph summarizes the conclusions and indicates the areas in which additional theoretical and experimental work is considered necessary.

\section{EXPLICIT DEPENDENCE OF TRANSPORT COEFFICIENTS ON DENSITY AND TEMPERATURE}

The Enskog-Chapman-Cowling ${ }^{1,2}$ solution of the linearized Boltzmann equation is appropriate for constructing analytical expressions of the tranport coefficients versus density and temperature, if the interaction forces are known. Using the additivity property of the linearized Boltzmann equation with respect to the perturbing causes which act against the equilibration of the velocity distribution function, expanding in a polynomial series the unknown functions of velocity of the first order approximation to the equilibrium solution, taking moments of the Boltzmann equation by multiplying it with terms of these expansions and integrating over the velocity space, leads to relations of the following form, as results from the formalism presented by Wilkins and Gyftopoulos: ${ }^{4}$

$$
\int F_{e, r}^{(m)}\left(v_{e}\right) d v_{e}=\sum_{n=0}^{\infty} z_{e, r}^{(n)}\left(n_{\xi}, T_{\xi}\right) \int G_{e}^{(m, n)}\left(v_{e}, n_{\xi}, T_{\xi}\right) d v_{e}
$$

where $\xi$ identifies the species, and $z_{e, r}^{(n)}$ represent the coefficients of the Sonine polynomial expansion of the unknown velocity functions $\vec{z}_{e}\left(\vec{v}_{e}\right)$ of the linearized Boltzmann equation solution which are used to calculate transport coefficients:

$$
\vec{z}_{e, r}\left(u_{e}\right)=\vec{u}_{e} \sum_{n=0}^{\infty} z_{e, r}^{(n)}\left(n_{\xi}, T_{\xi}\right) s_{n}^{3 / 2}\left(u_{e}^{2}\right) \quad r=a, b
$$

Here $\vec{u}_{e}$ is the velocity normalized to the electron thermal velocity $\overrightarrow{\mathrm{v}}_{\mathrm{eT}} \equiv\left(2 \mathrm{kT} \mathrm{e}^{/ \mathrm{m}_{\mathrm{e}}}\right)^{1 / 2}$.

By definition:

$$
\vec{u}_{e} \equiv\left(m_{e} / 2 k T_{e}\right)^{1 / 2} \vec{v}_{e}
$$




$$
s_{n}^{q}(x) \equiv \sum_{j=0}^{n} \frac{(-1)^{j}(n+q) ! x^{j}}{(q+j) !(n-j) !}
$$

The matrix elements:

$$
\delta_{e}^{(m, n)} \equiv \int G_{e}^{(m, n)}\left(v_{e}, n_{\xi}, T_{\xi}\right) d v_{e}
$$

have the dimension:

$$
\left[\delta \mathrm{e}^{(\mathrm{m}, \mathrm{n})}\right]=\mathrm{L}^{3} \mathrm{~T}^{-1}
$$

and the left side elements in (1) have zero dimension according to their definition:

$$
\begin{aligned}
& \beta_{e}^{m} \equiv \int F_{e, a}^{(m)}\left(v_{e}\right) d v_{e} \equiv \frac{1}{n_{e}} \int S_{m}^{3 / 2}\left(u_{e}^{2}\right) f_{e}^{o} d \vec{v}_{e}=\quad \begin{array}{l}
\frac{3}{2} \text { for } m=0 \\
0 \text { for } m \neq 0
\end{array} \\
& \gamma_{\mathrm{e}}^{\mathrm{m}} \equiv \int \mathrm{F}_{\mathrm{e}, \mathrm{b}}^{(\mathrm{m})}\left(\mathrm{v}_{\mathrm{e}}\right) d v_{\mathrm{e}} \equiv \frac{1}{n_{\mathrm{e}}} \int \mathrm{s}_{\mathrm{m}}^{3 / 2}\left(\mathrm{u}_{\mathrm{e}}^{2}\right)\left(\mathrm{u}_{\mathrm{e}}^{2}-\frac{5}{2}\right) \mathrm{f}_{\mathrm{e}}^{\mathrm{o}} \mathrm{d} \vec{v}_{\mathrm{e}}={ }_{0}^{-15 / 4 \text { for } \mathrm{m}=1} \text { for } \mathrm{m} \neq 1
\end{aligned}
$$

thus the dimension of the coefficients $z_{e, r}^{(n)}$ is:

$$
\left[\begin{array}{c}
z_{e, r}^{(n)}
\end{array}\right]=L^{-3} T
$$

The analytical dependence of the matrix elements $\delta_{e}^{(m, n)}$ on density and temperature results from the following considerations. Labeling with ee, ei, eo the electron-electron, electron-ion and electron-neutral atom contributions to the matrix element $\delta_{\mathrm{e}}^{(\mathrm{m}, \mathrm{n})}$, one may write:

$$
\delta_{\mathrm{e}}^{(\mathrm{m}, \mathrm{n})}=\delta_{\mathrm{e}, \mathrm{ee}}^{(\mathrm{m}, \mathrm{n})}+\delta_{\mathrm{e}, \mathrm{ei}}^{(\mathrm{m}, \mathrm{n})}+\delta_{\mathrm{e}, \mathrm{eo}}^{(\mathrm{m}, \mathrm{n})}
$$

The term $\delta_{e, e e}^{(m, n)}$ is identified in Chapman-Cowling ${ }^{2}$ with a sum of two terms: 
5

$$
\begin{aligned}
\delta_{e, e e}^{(m, n)} & \equiv \frac{1}{n_{e}^{2}} \int f_{e}^{o} f^{o}\left(s_{n} \vec{u}_{e}+s_{n} \vec{u}-s_{n} \vec{u}_{e}^{\prime}-s_{n} \vec{u}^{\prime}\right) s_{m} \vec{u}_{e} g \sigma d^{2} \Omega d \vec{v}_{d} \vec{v}_{e} \\
& \equiv\left[s_{m} \vec{u}_{e}, s_{n} \vec{u}_{e}\right]_{e} \\
& =\lim _{i \rightarrow e}\left[s_{n} \vec{u}_{e}, s_{m} \vec{u}_{i}\right]_{e i}+\lim _{i \rightarrow e}\left[s_{n} \vec{u}_{e}, s_{m} \vec{u}_{e}\right]_{e i}
\end{aligned}
$$

where:

$$
\begin{aligned}
& {\left[s_{n} \vec{u}_{e}, s_{m} \vec{u}_{i}\right]_{e i} \equiv \frac{1}{n_{e}^{n_{i}}} \int f_{e}^{o} f_{i}^{o}\left(s_{n} \vec{u}_{e}-s_{n} \vec{u}_{e}^{\prime}\right) s_{m} \vec{u}_{i} g \sigma d^{2} \Omega d \vec{v}_{i} d \vec{v}_{e}} \\
& {\left[s_{n} \vec{u}_{e}, s_{m} \vec{u}_{e}\right]_{e i} \equiv \frac{1}{n_{e} n_{i}} \int f_{e}^{o} f_{i}^{o} s_{n} \vec{u}_{e}-s_{n} \vec{u}_{e}^{\prime} s_{m} \vec{u}_{e} g \sigma d^{2} \Omega d \vec{v}_{i} d \vec{v}_{e}}
\end{aligned}
$$

and:

$$
s_{p} \vec{u}_{s} \equiv s_{p}^{3 / 2}\left(u_{s}\right) \vec{u}_{s} \quad p=m, n \quad s=e, i
$$

According to $(9.33,1),(9.33,2)$ in Chapman-Cowling ${ }^{2}$ :

$$
\left[s_{n} \vec{u}_{e}, s_{m} \vec{u}_{i}\right]_{e i}=\delta M_{i}^{m+\frac{1}{2}} M_{e}^{n+\frac{1}{2}} \sum_{r, l} A_{m n r} \Omega_{e i}^{(l)}(r)
$$

where:

$$
\begin{aligned}
& \Omega_{e i}^{(\ell)}(r) \equiv \Pi^{1 / 2} \int e^{-\tilde{g}^{2}} \tilde{g}^{2 r+2}\left(1-\cos ^{\ell} \chi\right) g b d b d \widetilde{g} \\
& \equiv\left(\frac{k T}{2 \Pi m_{e i}}\right)^{1 / 2} \int e^{-\tilde{g}^{2}} \tilde{g}^{2 r+3} \phi_{\mathrm{ei}}^{(l)}(\mathrm{g}) \mathrm{d} \tilde{\mathrm{g}} \\
& \phi_{\mathrm{ei}}^{(\ell)}(\mathrm{g}) \equiv 2 \pi \int\left(1-\cos ^{\ell} \chi\right) \mathrm{bd} b \equiv 2 \pi \int\left(1-\cos ^{\ell} \chi\right) \sigma_{\mathrm{ei}}(g, \chi) \sin \chi \mathrm{d} \chi(9) \\
& m_{e i} \equiv \frac{m_{e} m_{i}}{m_{e}+n_{i}} \\
& M_{e} \equiv \frac{m_{e}}{m_{e}+m_{i}} ; \quad M_{i} \equiv \frac{m_{i}}{m_{e}+m_{i}}
\end{aligned}
$$




$$
\tilde{\mathrm{g}} \equiv\left(\frac{\mathrm{m}_{\mathrm{ei}}}{2 \mathrm{kT}}\right)^{1 / 2} \mathrm{~g}_{\mathrm{ei}}
$$

and where unlike in (2):

$$
u_{e} \equiv\left(\frac{m_{e}}{2 k T}\right)^{1 / 2} v_{e} ; \quad u_{i} \equiv\left(\frac{m_{i}}{2 k T}\right)^{1 / 2} v_{i}
$$

the parameter $\mathrm{T}$ being the same for all species. The $A_{\mathrm{mnr} \ell}$ are numerical coefficients evaluated in [2].

For electrostatic forces the differential cross section is:

$$
\sigma_{\mathrm{ei}}=\left(\frac{z_{\mathrm{i}} \mathrm{e}^{2}}{\epsilon_{\mathrm{o}} \mathrm{m}_{\mathrm{ei}} \mathrm{g}^{2}}\right)^{2} \frac{1}{(1-\cos \chi)^{2}}
$$

and thus:

$$
\begin{aligned}
& \phi_{\mathrm{ei}}^{(\ell)}(g)=2 \pi\left(\frac{z_{\mathrm{i}} \mathrm{e}^{2}}{2 \mathrm{kT} \epsilon_{\mathrm{o}} \tilde{g}^{2}}\right)^{2} \quad \int \frac{1-\cos ^{\ell} x}{(1-\cos x)^{2}} \sin x \mathrm{~d} x \\
& =2 \pi\left(\frac{z_{i} e^{2}}{2 k T \epsilon_{0} \widetilde{g}^{2}}\right)^{2} \int_{0}^{v_{01}}\left[1-\left(\frac{v_{0}^{2}-1}{v_{0}^{2}+1}\right)^{l}\right] v_{0} d v_{0}
\end{aligned}
$$

where:

$$
v_{0} \equiv \frac{2 k T \epsilon_{0} b \tilde{g}^{2}}{z_{i} e^{2}}
$$

and where $v_{o l}$ denotes the upper limit of $v_{0}$.

The finite practical limit assigned to $v_{01}$ in order to eliminate the divergence of the integral (11) is based on the observation that particles farther apart than the Debye length $\mathrm{D}$ are less numerous than the closer encounters and do not undergo 
binary interactions. Setting $b=D$ in relation (12) and substituting $\tilde{g}^{2}$ by its mean value equal to 2 leads to the following expression of the cutoff limit of the integral in (11):

$$
v_{o 1} \equiv \frac{4 D k T}{z_{i} e^{2}}
$$

The Debye length in a binary mixture is approximately equal to:

$$
D \equiv\left(\frac{k T}{4 \Pi z_{i} e^{2} n_{e}}\right)^{1 / 2}
$$

Substituting (11) into (8) and taking into account (13) and (14) yields an expression for $\Omega_{12}^{(\ell)}(r)$ of the form:

$$
\begin{aligned}
& \Omega_{\mathrm{ei}}^{(\ell)}(r)=\left(\frac{2 \Pi \mathrm{kT}}{\mathrm{m}_{\mathrm{ei}}}\right)^{1 / 2}\left(\frac{\mathrm{Z}_{\mathrm{i}} \mathrm{e}^{2}}{2 \mathrm{k} \dot{\mathrm{T}} \epsilon_{\mathrm{o}} \tilde{\mathrm{g}}^{2}}\right)^{2} \\
& x \int^{-\widetilde{g}^{2}} \cdot \tilde{g}^{2 r-1} \quad\left[1-\left(\frac{v_{o}^{2}-1}{v_{0}^{2}+1}\right)^{\ell}\right] v_{0} d v_{0} d \tilde{g} \\
& \equiv T^{-3 / 2} F\left(n_{e}, T\right)
\end{aligned}
$$

where the truncation of the integral in (11) introduces a supplementary dependence $\mathrm{F} \mathrm{n}_{\mathrm{e}}, \mathrm{T}$ on temperature and electron density. The function $\mathrm{F}$ varies slowly with temperature and density as may be seen from expression (10) for $l=2$, which is the only value of $\ell$ needed in the present evaluation: 


$$
\begin{aligned}
& \phi_{\mathrm{ei}}^{(2)} \equiv \phi_{\mathrm{ei}}^{(2)}\left(\mathrm{g}, \mathrm{n}_{\mathrm{e}}, \mathrm{T}\right) \simeq \Pi\left(\frac{z_{\mathrm{i}} \mathrm{e}^{2}}{\mathrm{kT} \epsilon_{\mathrm{o}} \widetilde{g}^{2}}\right)^{2} 3\left[\operatorname{lnT}+\ln \frac{\mathrm{k}}{z_{\mathrm{i}} \mathrm{e}^{2}}\left(\frac{4}{\Pi \mathrm{n}_{\mathrm{e}}}\right)\right]^{1 / 3} \\
& =4 \Pi\left(\frac{z_{\mathrm{i}} \mathrm{e}^{2}}{2 \mathrm{kT} \epsilon_{\mathrm{o}} \tilde{\mathrm{g}}^{2}}\right)^{2}\left\{\ln 1+\left(\frac{4 \mathrm{k}^{3} \mathrm{~T}^{3}}{\Pi \mathrm{z}_{\mathrm{i}}^{3} \mathrm{e}^{6} \mathrm{n}_{\mathrm{e}}}\right)-\frac{\frac{4 \mathrm{k}^{3} \mathrm{~T}^{3}}{\pi z_{\mathrm{i}}^{3} \mathrm{e}^{6} \mathrm{n}_{\mathrm{e}}}}{1+\frac{4 \mathrm{k}^{3} \mathrm{~T}^{3}}{\pi z_{\mathrm{i}}^{3} \mathrm{e}^{6} \mathrm{n}_{\mathrm{e}}}}\right\}
\end{aligned}
$$

In a similar way, according to $(9.4,15)$ in Chapman-Cowling ${ }^{2}$ one may evaluate the second bracket integral in expression (6):

$$
\left[S_{n} \vec{u}_{e}, S_{m} \vec{u}_{e}\right]_{e i}=8 \sum_{r, \ell} A_{m n r \ell}^{\prime} \Omega_{e i}^{(l)}(r)
$$

Combining (5), (7) and (17) yields the electron-electron contribution to the $\delta_{\mathrm{e}}^{(\mathrm{m}, \mathrm{n})}$ matrix element:

$$
\delta_{e, e e}^{(m, n)}=\sum_{r, \ell}\left[\left(\frac{1}{2}\right)^{m+n+1} A_{m n r \ell}+A_{m n r \ell}^{\prime}\right] \Omega_{e i}^{(\ell)}(r)
$$

which for $\mathrm{m}, \mathrm{n}=0,1,2$ as given in $(9.6,7)-(9.6,10)$ of $[2]$ is:

$$
\begin{aligned}
& {\left[s_{0} \vec{u}_{e}, s_{m} \vec{u}_{e}\right]_{e}=0} \\
& {\left[s_{1} \vec{u}_{e}, s_{1} \vec{u}_{e}\right]_{e}=4 \Lambda_{e}^{(2)}(2)} \\
& {\left[s_{1} \vec{u}_{e}, s_{2} \vec{u}_{e}\right]_{e}=7 \Omega_{e}^{(2)}(2)-2 \Omega_{e}^{(2)}(3)} \\
& {\left[s_{2} \vec{u}_{e}, s_{2} \vec{u}_{e}\right]_{e}=\frac{77}{4} \Omega_{e}^{(2)}(2)-7 \Omega_{e}^{(2)}(3)+\Omega_{e}^{(2)}(4)}
\end{aligned}
$$

where $\Omega^{(2)}(r)$ is provided by (8) and (16) substituting $T$ with $T_{e}$ and $m_{e i}$ with $m_{e} / 2$. 
For a mixture of species thermalized around their individual temperatures the electron-ion term in (3) is evaluated by Wilkins and Gyftopoulos ${ }^{4}$ using the following approximative expression:

$$
\delta_{e, e i}^{(m, n)}=\frac{1}{n_{e}^{2}} \int f_{e}^{o} u_{e}^{2} v_{e i} s_{m} s_{n} d \vec{v}_{e}
$$

where the 'momentum collision frequency' $v_{e i}$ in the approximation $v_{e} \gg v_{i}$ and $m_{\mathrm{e}} \ll \mathrm{m}_{\mathrm{i}}$ is:

$$
v_{e i} \equiv n_{i} v_{e} \int(1-\cos x) \sigma_{e i}\left(v_{e}, x\right) d^{2} \Omega
$$

Following Trubnikov $^{5}$ in eliminating the divergence by choosing the minimum value of the deflection angle to be the ratio of the impact parameter for $\chi=\frac{\Pi}{2}$ and the Debye length:

$$
\chi_{\min }=\frac{b(\Pi / 2)}{D}=\frac{z_{i} e^{3}}{k T_{e}}\left(\frac{T_{e}+T_{i}}{T_{e} T_{i}} \frac{\Pi n_{e}}{k}\right)^{1 / 2}
$$

leads to the density and temperature dependence of the electron-ion term as expressed below:

$$
\begin{gathered}
\delta_{e, e i}^{(m, n)}=\frac{n_{i}}{n_{e}} \frac{2^{3 / 2} n^{1 / 2} e^{4}}{\epsilon_{o}^{2} m_{e}^{1 / 2} k^{3 / 2}} T_{e}^{3 / 2} \text { ln } \Lambda \int e^{-u_{e}^{2}} u_{e} S_{m} S_{n} d u_{e} \\
\Lambda \equiv \frac{2}{1-\cos \chi_{\min }}
\end{gathered}
$$

An electron-neutral atom term may be evaluated as in [4] based on the same approximations used in the electron-ion term: 


$$
\begin{aligned}
& \delta_{e, e o}^{(m, n)}=\frac{1}{n_{e}^{2}} \int f_{e}^{o} u_{e}^{2} v_{e o} S_{m} s_{n} d \vec{v}_{e} \\
& \quad \equiv \frac{n_{o}}{n_{e}} \frac{1}{\Pi^{3 / 2}}\left(\frac{2 k T_{e}}{m_{e}}\right)^{1 / 2} \int e^{-u_{e}^{2}} u_{e}^{5} s_{m} S_{n} Q_{e o}\left(v_{e}\right) d u_{e}
\end{aligned}
$$

where the total cross section is:

$$
\mathrm{Q}_{\mathrm{eo}}\left(\mathrm{v}_{\mathrm{e}}\right) \equiv 2 \pi \int(1-\cos \chi) \sigma_{\mathrm{eo}}\left(\mathrm{v}_{\mathrm{e}}, \chi\right) \sin \chi \mathrm{d} \chi
$$

The temperature dependence of expression (25) is determined by the presence of a $Q_{e o}\left(v_{e}\right)$ function in the integrant summed over a $u_{e} \sim T_{e}^{-1 / 2} v_{e}$ variable, as results from approximating $Q_{e o}$ with a sum of segments of constant slope $\partial Q_{e o} / \partial v_{e}$ and observing that $\partial Q_{e o} / \partial v_{e}$ is independent of temperature contrary to $\partial Q_{e o} / \partial u_{e}$, and that

$$
\begin{gathered}
\frac{d Q}{d v} d v=\frac{d Q}{d u} d u: \\
Q_{e o}\left(u_{e}\right)=Q_{e o}\left[u_{e}\left(v_{e}\right)\right]=Q^{0}+\int \frac{d Q_{e o}}{d v_{e}} d v_{e} \\
=\sum_{s=0}^{s_{M^{-1}}}\left[Q_{s}+\frac{2 k T_{e}^{1 / 2}}{m_{e}}\left(\frac{\partial Q}{\partial v}\right)_{s, s+1}\left(u-u_{s}\right)\right]
\end{gathered}
$$

where:

$$
Q^{0} \equiv Q_{e o}\left(v_{e}=u_{e}=0\right)
$$

$s_{M}-1$ are the number of fracture points of $Q_{e o}\left(u_{e}\right)$ along the $u_{e}$ direction and $u_{s_{M}}$ may be finite or infinite.

In this case (25) becomes: 


$$
\begin{aligned}
& \delta_{e, e o}^{(m, n)} \simeq \frac{n_{0}}{n_{e}} \frac{1}{\Pi^{3 / 2}}\left(\frac{2 k T e}{m_{e}}\right)^{1 / 2} \\
& x \sum_{s=0}^{s_{M}-1}\left\{\left[Q_{s}-v_{s}\left(\frac{\partial Q}{\partial v}\right)_{s, s+1}\right] \int_{u_{s}}^{u_{s+1}} e^{-u^{2}} u^{5} s_{m} s_{n} d u\right. \\
& \left.+\left(\frac{2 k T}{m_{e}}\right)^{1 / 2}\left(\frac{\partial Q}{\partial u}\right)_{s, s+1} \int_{u_{s}}^{u_{s+1}} e^{-u^{2} u^{6} s_{m} s_{n} d u}\right\}
\end{aligned}
$$

For a constant slope $\partial Q_{e o} / \partial v_{e}$ along the practical interval, expression (28) becomes:

$$
\delta \delta_{e, e o}^{(m, n)}=\frac{n_{0}}{n_{e}} \frac{1}{\pi^{3 / 2}}\left(\frac{2 k T e}{m_{e}}\right)^{1 / 2} \int_{0}^{\infty} e^{-u^{2}} u^{5} S_{m} S_{n}\left[Q^{0}+\left(\frac{2 k T e}{m_{e}}\right)^{1 / 2}\left(\frac{\partial Q}{\partial v_{e}}\right)_{v_{e}=0} u\right] d u(29)
$$

The values of $Q$ and $\partial Q / \partial v$ for various values $v_{s}$ of the variable $v$, respectively, $u_{s}$ of the variable $u$ are independent of temperature. The two integrals in (28) depend on temperature through their limits according to the transformation

$$
\mathrm{u}=\left(\frac{\mathrm{m}}{2 \mathrm{kT}}\right)^{1 / 2} \mathrm{v}
$$

and may be integrated analytically leading to products of $e^{-u^{2}}$ and polynomials in $u^{2}$.

For the first two Sonine polynomials $\mathrm{S}_{0}, \mathrm{~S}_{1}$, the integrals in (28) are:

$$
\begin{aligned}
& \int e^{-u^{2}} u^{5} s_{0} s_{0} d u=\int e^{-u^{2}} u^{5} d u
\end{aligned}
$$

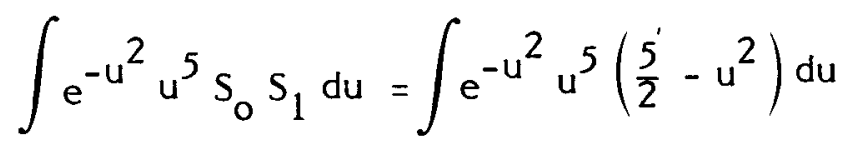

$$
\begin{aligned}
& \int e^{-u^{2}} u^{5} s_{1} s_{1} d u=\int e^{-u^{2}} u^{5}\left(\frac{5}{2}-u^{2}\right)^{2} d u
\end{aligned}
$$




$$
\begin{aligned}
& \int e^{-u^{2}} u^{g} d u=-e^{-u^{2}}\left(12+12 u^{2}+6 u^{4}+2 u^{6}+\frac{1}{2} u^{8}\right) \\
& \int e^{-u^{2}} u^{7} d u=-e^{-u^{2}}\left(3+3 u^{2}+\frac{3}{2} u^{4}+\frac{1}{2} u^{6}\right) \\
& \int e^{-u^{2}} u^{5} d u=-e^{-u^{2}}\left(1+u^{2}+\frac{1}{2} u^{4}\right) \\
& \int e^{-u^{2}} u^{6} s_{o} s_{o} d u=\int e^{-u^{2}} u^{6} d u \\
& \int e^{-u^{2}} u^{6} s_{o} s_{1} d u=\int e^{-u^{2}} u^{6}\left(\frac{5}{2}-u^{2}\right) d u \\
& \int e^{-u^{2}} u^{6} s_{1} s_{1} d u=\int e^{-u^{2}} u^{6}\left(\frac{5}{2}-u^{2}\right)^{2} d u \\
& \int e^{-u^{2}} u^{10} d u=\frac{g ! !}{2} \int e^{-u^{2}} d u-e^{-u^{2}} \frac{g ! !}{2^{5}}\left(u+\frac{2}{3} u^{3}+\frac{2^{2}}{5 ! !} u^{5}+\frac{2^{3}}{7 ! !} u^{7}+\frac{2^{4}}{g ! !} u^{g}\right) \\
& \int e^{-u^{2}} u^{8} d u=\frac{7 ! !}{2^{4}} \int e^{-u^{2}} d u-e^{-u^{2}}\left(\frac{7 \cdot 5 \cdot 3}{2^{4}} u+\frac{7 \cdot 5}{2^{3}} u^{3}+\frac{7}{2^{2}} u^{5}+\frac{1}{2} u^{7}\right) \\
& \int e^{-u^{2}} u^{6} d u=\frac{5 ! !}{2^{3}} \int e^{-u^{2}} d u-e^{-u^{2}}\left(\frac{5 \cdot 3}{2^{3}} u+\frac{5}{2^{2}} u^{3}+\frac{1}{2} u^{5}\right)
\end{aligned}
$$

They can be used for evaluating the second order approximation of the mobility $\mu_{\mathrm{e}}[2]$ as shown in the next paragraph.

In conclusion the density and temperature dependence of the $\delta_{\mathrm{e}}^{(\mathrm{m}, \mathrm{n})}$ matrix element, as results from expressions $[(18),(8),(16)],[(23),(24),(22)](25)$ and (28) may be summarized as follows: 


$$
\begin{gathered}
\delta_{e}^{(m, n)}=\delta_{e, e e}^{(m, n)}\left(n_{e}, T_{e}\right)+\frac{n_{i}}{n_{e}} \hat{\delta}_{e, e i}^{(m, n)}\left(n_{e}, T_{e}, T_{i}\right)+\frac{n_{o}}{n_{e}} \hat{\delta}_{e, e o}^{(m, n)}\left(T_{e}\right) \\
\delta_{e}^{(m, n)}=T_{e}^{-3 / 2} \hat{\delta}_{e, e e}^{(m, n)}\left(n_{e}, T_{e}\right)+\frac{n_{i}}{n_{e}} T_{e}^{-3 / 2} \hat{\delta}_{e, e i}^{(m, n)}\left(n_{e}, T_{e}, T_{i}\right)+\frac{n_{o}}{n_{e}} T_{e}^{1 / 2} \hat{\delta}_{e, e o}^{(m, n)}\left(T_{e}\right)
\end{gathered}
$$

where the $\hat{\delta}_{e, e e}, \hat{\delta}_{e, e i}$ and $\hat{\delta}_{e, e o}$ functions are defined to be weakly dependent of densities and the $\hat{\hat{\delta}}_{\mathrm{e}, \mathrm{ee}}$, $\hat{\hat{\delta}}_{\mathrm{e}, \mathrm{ei}}$ and $\hat{\hat{\delta}}_{\mathrm{e}, \mathrm{eo}}$ functions are defined to be weakly dependent of temperature; in particular $\hat{\hat{\delta}}_{\mathrm{e}, \mathrm{eo}}$ is independent of temperature for a hard sphere cross section.

According to their definition:

$$
\begin{aligned}
& \delta_{e, e e} \equiv \hat{\delta}_{e, e e} \quad \mathrm{~T}_{\mathrm{e}}^{-3 / 2} \hat{\hat{\delta}}_{\mathrm{e}, \mathrm{ee}} \\
& \delta_{e, e i} \equiv \frac{n_{i}}{n_{e}} \hat{\delta}_{e, e i} \equiv \frac{n_{i}}{n_{e}} T_{e}^{-3 / 2} \hat{\delta}_{e, e i} \\
& \delta_{e, e o} \equiv \frac{n_{o}}{n_{e}} \hat{\delta}_{e, e o} \equiv \frac{n_{0}}{n_{e}} T_{e}^{1 / 2} \hat{\hat{\delta}}_{e, e o} \equiv \frac{n_{o}}{n_{e}} T_{e}^{1 / 2}\left(\hat{\delta}_{e, e o}^{I}+T_{e}^{1 / 2} \hat{\delta}_{e, e o}^{I I}\right) \\
& \underset{e, e e}{\hat{\delta}(m, n)}\left(n_{e}, T_{e}\right) \equiv \sum_{r, l=2} 8\left[\left(\frac{1}{2}\right)^{m+n+1} A_{m n r 2}+A_{m n r 2}^{\prime}\right] \\
& x \frac{\Pi^{1 / 2} e^{4}}{m_{e}^{1 / 2} k^{3 / 2}} 3\left[\operatorname{lnT} e+\ln \frac{k}{e^{2}}\left(\frac{4}{\Pi_{n}}\right)^{1 / 3}\right] \\
& \hat{\hat{\delta}}_{\mathrm{e}, \mathrm{ei}}^{(\mathrm{m}, \mathrm{n})}\left(\mathrm{n}_{\mathrm{e}}, \mathrm{T}_{\mathrm{e}}, \mathrm{T}_{\mathrm{i}}\right) \equiv \frac{2^{3 / 2} \Pi^{1 / 2} \mathrm{e}^{4} \mathrm{k}^{-3 / 2}}{\epsilon_{\mathrm{o}}^{2} \mathrm{~m}_{\mathrm{e}}^{1 / 2}} \text { ln } \frac{2}{1-\cos \frac{z_{\mathrm{i}} \mathrm{e}^{3}}{\mathrm{kT}}\left(\frac{\mathrm{T}_{\mathrm{e}}+\mathrm{T}_{\mathrm{i}}}{-\mathrm{T}_{\mathrm{T}} \mathrm{T}_{\mathrm{i}}} \frac{\Pi \mathrm{n}_{\mathrm{e}}}{\mathrm{k}}\right)^{1 / 2}} \\
& \int_{0}^{\infty} e^{-u^{2} u s_{m}\left(u^{2}\right) s_{n}\left(u^{2}\right) d u}
\end{aligned}
$$




$$
\begin{aligned}
& \hat{\delta}_{e, e o}^{(m, n)}\left(T_{e}\right) \equiv \frac{2^{1 / 2} k^{1 / 2}}{n^{3 / 2} m_{e}^{1 / 2}} \int e^{-u_{e}^{2}} u_{e}^{5} S_{m}\left(u_{e}^{2}\right) S_{n} u_{e}^{2} Q_{e o}\left(v_{e}\right) d u \\
& \hat{\hat{\delta}}_{e, \mathrm{~m}, \mathrm{n}) \mathrm{I}}\left(T_{\mathrm{e}}\right) \equiv \frac{1}{\Pi^{3 / 2}}\left(\frac{2 k}{m_{e}}\right)^{1 / 2} \sum_{s=0}^{s_{M^{-1}}}\left[Q_{s}-v_{s}\left(\frac{\partial Q}{\partial v}\right)_{s, s+1}\right] \int_{u_{s}}^{u_{s+1}} e^{-u^{2}} u^{5} s_{m} s_{n} d u \\
& \hat{\delta}_{e, e o}^{(m, n) I I}\left(T_{e}\right) \equiv \frac{2 k}{\Pi^{3 / 2} m_{e}}\left(\frac{\partial Q}{\partial v}\right)_{s, s+1} \int_{u_{s}}^{u_{s+1}} e^{-u^{2}} s_{m} s_{n} u^{6} d u \\
& \hat{\delta}_{e, e o}\left(\frac{\partial Q}{\partial v}=c t\right) \equiv \frac{1}{\Pi^{3 / 2}}\left(\frac{2 k}{m_{e}}\right)^{1 / 2} Q^{0} \int_{0}^{\infty} e^{-u^{2}} u^{5} S_{m} S_{n} d u \\
& \hat{\hat{\delta}}_{e, e o}^{I I}\left(\frac{\partial Q}{\partial v}=c t\right) \equiv \frac{1}{\Pi^{3 / 2}} \frac{2 k}{m_{e}}\left(\frac{\partial Q}{\partial v}\right)_{v_{e}=0} \int_{0}^{\infty} e^{-u^{2} u^{6} S_{m} S_{n} d u}
\end{aligned}
$$

where:

$$
\frac{\partial}{\partial \mathrm{T}_{\mathrm{e}}} \hat{\hat{\delta}}_{\mathrm{e}, \mathrm{eo}}^{\mathrm{I}}=0 \quad \frac{\partial}{\partial \mathrm{T}_{\mathrm{e}}} \quad \hat{\hat{\delta}}_{\mathrm{e}, \mathrm{II}}^{\mathrm{II}}=0
$$

The functions $\hat{\hat{\delta}}_{\mathrm{e}, \mathrm{ee}}^{\ell=2}$ and $\hat{\hat{\delta}}_{\mathrm{e}, \mathrm{ei}}$ are weakly dependent on electron density and temperature for practical variations of these two parameters due to the logarithmic functionality.

It results that in a first approximation in which the logarithmic functions are averaged over the electron density and temperature range of interest, Eq. (30) becomes:

$$
\begin{aligned}
& \delta_{e}^{(m, n)} \simeq T_{e}^{-3 / 2}[\underbrace{\overline{\hat{\lambda}}}_{e, e e}(m, n)+\frac{n_{i}}{n_{e}} \overline{\hat{\delta}}_{e, e i}(m, n)+\frac{n_{o}}{n_{e}} T_{e}^{2} \hat{\delta}_{e, e o}\left(T_{e}\right)]
\end{aligned}
$$

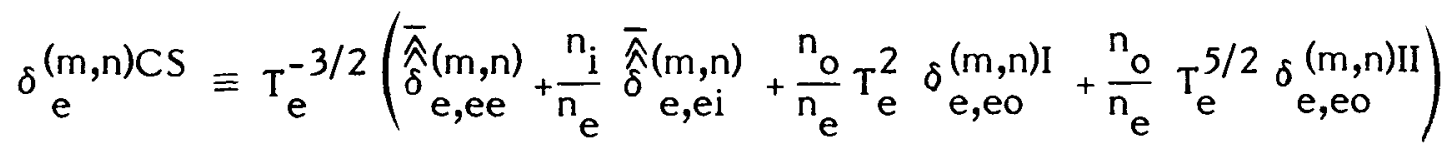


where the averages are effectuated with respect to density and temperature, results from (38) $-(42)$, and $\delta{ }_{\mathrm{e}}^{(\mathrm{m}, \mathrm{n}) \mathrm{CS}}$ corresponds to constant slope $\mathrm{Q}_{\text {eo }}\left(\mathrm{v}_{\mathrm{e}}\right)$.

Substituting (31) and (32) in (1) the density and temperature dependence of the unknown functions $z_{e, r}^{(n)}$ when the indices $m$ and $n$ are truncated to $n_{M}$ has the following explicit form:

For a general cross section:

$$
\begin{aligned}
z_{e, r\left[n_{\left.M^{+1}\right]}\right.}^{(n)}=\frac{\sum_{k=0}^{n_{M}} \hat{x}_{r k}^{(n)}\left(\frac{n_{o}}{n_{e}}\right)^{k}}{\sum_{j=0}^{n_{M}+1} \hat{Y}_{j}\left(\frac{n_{0}}{n_{e}}\right)^{j}}=\frac{\left(T_{e}^{-3 / 2}\right)^{n_{M}} \sum_{k=0}^{n_{M}} \hat{\hat{x}}_{r k}^{(n)}\left(\frac{n_{o}}{n_{e}} T_{e}^{2}\right)^{k}}{\left(T_{e}^{-3 / 2}\right)^{n_{M}+1} \sum_{j=0}^{n_{M}+1} \hat{\hat{Y}}_{j}\left(\frac{n_{0}}{n_{e}} T_{e}^{2}\right)^{j}} \\
=T_{e}^{3 / 2} \frac{\sum_{k=0}^{n_{M}} \hat{\hat{X}}_{r k}^{(n)}\left(\frac{n_{0}}{n_{e}} T_{e}^{2}\right)^{k}}{\sum_{j=0}^{n_{M}^{+1}} \hat{\hat{Y}}_{j}\left(\frac{n_{0}}{n_{e}} T_{e}^{2}\right)^{j}}
\end{aligned}
$$

where $\hat{Y}_{j}$ are the coefficients of $\left(\mathrm{n}_{\mathrm{o}} / \mathrm{n}_{e}\right)^{j}$ in the expansion of the principal determinant $|\delta \underset{e}{(m, n)}|$ of order $n_{M}+1$, of the system of Eqs. (1) and $\stackrel{\hat{\vartheta}}{Y}_{j}$ are the coefficients of $\left[\left(n_{0} / n_{e}\right)\left(T_{e}^{2}\right)^{d}\right]$ in the expansion of the same determinant after factoring out $T^{-3 / 2}$ from each element; $\hat{X}_{r k}^{(n)}$ are the coefficients of $\left(n_{o} / n_{e}\right)^{k}$ in the expansion of the determinant of order, $n_{M}+1$, conjugate with the unknown $z_{e}^{(n)}, r$, in the system of Eqs. (1) and $\hat{x}_{r k}^{(n)}$ are the coefficients of $\left[\left(n_{d} / n_{e}\right)\left(T_{e}^{2}\right)\right]^{k}$ in the expansion of the same determinant after factoring out $\dot{\mathrm{T}}^{-3 / 2}$ from each element which is of the form (31).

As previously with the $\delta_{S}^{\prime}$, the single hatted $\hat{X}$ and $\hat{Y}$ suggest that they are weak functions of densities, while the double hatted $\hat{X}$ and $\hat{\hat{Y}}$ are functions of temperature primarily through $\hat{\delta}_{e, e o}$ if one neglects the very weak temperature dependence of $\hat{\delta}_{\mathrm{e}, \mathrm{eo}}$ and $\hat{\delta}_{\mathrm{e}, \mathrm{ei}}$. 
For a cross section independent of $v_{e}$ (hard shpere):

$$
\begin{aligned}
& z_{e, r\left[n_{M}^{+1}\right]}^{(n) H S}=T_{e}^{3 / 2} \frac{\sum_{k=0}^{n_{M}} \hat{\hat{x}}_{r k}^{(n) H S}\left(\frac{n_{o}}{n_{e}} T_{e}^{2}\right)^{k}}{\sum_{j=0}^{n_{M}^{+1}} \hat{\hat{Y}}_{j}^{H S}\left(\frac{n_{o}}{n_{e}} T_{e}^{2}\right)^{j}} \\
& z_{e, r\left[n_{M^{+1}}\right]}^{(n) C S}=T_{e}^{3 / 2} \frac{\sum_{k=0}^{M}\left[\hat{x}_{r k}^{(n) C S, I}\left(\frac{n_{o}}{n_{e}} T_{e}^{2}\right)+\hat{\hat{x}}_{r k}^{(n) C S, I I}\left(\frac{n_{o}}{n_{e}} T_{e}^{5 / 2}\right)\right]}{\sum_{j=0}^{n_{M}+1}\left[\hat{\hat{Y}}_{j}^{C S, I}\left(\frac{n_{0}}{n_{e}} T_{e}^{2}\right)+\hat{\hat{Y}}_{j}^{C S, I I}\left(\frac{n_{o}}{n_{e}} T_{e}^{5 / 2}\right)\right]}
\end{aligned}
$$

where the coefficients $\hat{\hat{X}}^{(n) H S}, \hat{\hat{Y}}^{H S}, \hat{\mathrm{X}}^{(n) C S}, \stackrel{\hat{\mathrm{Y}}}{\mathrm{SC}}$ are independent of temperature.

The transport coefficients have thus the following density and temperature dependence taking into account their definition and expression (44);

The electron mobility:

$$
\begin{aligned}
& \mu_{e} \equiv \frac{2 e}{3 m_{e} n_{e}^{2}} \int f_{e}^{o} u_{e} z_{e a} d \vec{v}_{e}
\end{aligned}
$$

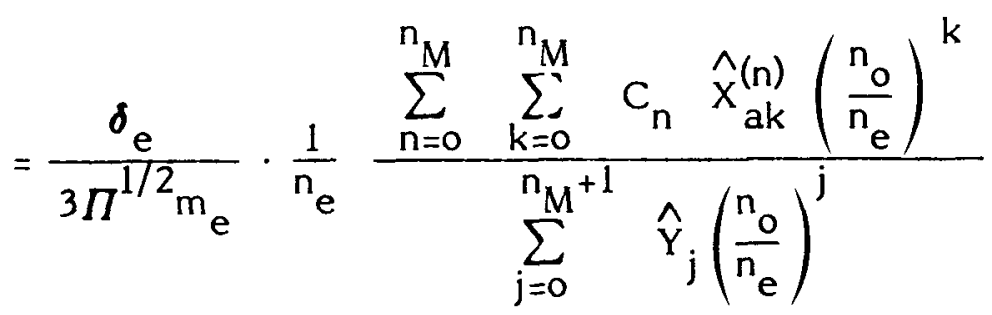

$$
\begin{aligned}
& =\frac{e}{3 \Pi^{1 / 2} m_{e}} \cdot \frac{1}{n_{e}} \frac{\sum_{k=0}^{n_{M}} \hat{L}_{a k}\left(\frac{n_{o}}{n_{e}}\right)^{k}}{\sum_{j=0}^{n_{M}} \hat{Y}_{j}\left(\begin{array}{l}
n_{0} \\
n_{e}
\end{array}\right)^{j}} \\
& =\frac{\delta_{e}}{3 \Pi^{1 / 2} m_{e}} \frac{T_{e}^{3 / 2}}{n_{e}} \frac{\sum_{k=0}^{n_{M}} \hat{\hat{L}}_{a k}\left(\frac{n_{o}}{n_{e}} T_{e}^{2}\right)^{k}}{\sum_{j=0}^{n_{M}+1} \hat{\hat{x}}_{j}\left(\frac{n_{o}}{n_{e}} T_{e}^{2}\right)^{j}}
\end{aligned}
$$


The thermal diffusion coefficient:

$$
\begin{aligned}
& k_{e}^{T} \equiv \frac{1}{\mu_{e}} \frac{2 e}{3 m_{e} n_{e}^{2}} \int f_{e}^{o} u_{e} z_{e b} d \vec{v}_{e} \\
& =\frac{1}{\mu_{e}} \frac{8 \mathrm{e}}{3 \Pi^{1 / 2} m_{e}} \frac{1}{n_{e}} \frac{\sum_{n=0}^{n_{M}} \sum_{k=0}^{n_{M}} c_{n} \hat{x}_{b k}^{(n)}\left(\frac{n_{o}}{n_{e}}\right)^{k}}{\sum_{j=0}^{n_{M}+1} \hat{Y}_{j}\left(\frac{n_{o}}{n_{e}}\right)^{j}} \\
& =\frac{1}{\mu_{e}} \frac{8 e}{3 \Pi^{1 / 2} m_{e}} \frac{1}{n_{e}} \frac{\sum_{k=0}^{n_{M}} \hat{L}_{b k}\left(\frac{n_{0}}{n_{e}}\right)^{k}}{\sum_{j=0}^{n_{M}+1} \hat{Y}_{j}\left(\frac{n_{0}}{n_{e}}\right)^{j}} \\
& =\frac{1}{\mu_{e}} \frac{e}{3 \Pi^{1 / 2} m_{e}} \frac{T_{e}^{3 / 2}}{n_{e}} \frac{\sum_{k=0}^{n_{M}} \hat{\hat{L}}_{b k}\left(\frac{n_{o}}{n_{e}} T_{e}^{2}\right)^{k}}{\sum_{j=0}^{n_{M}+1} \hat{\hat{Y}}_{j}\left(\frac{n_{0}}{n_{e}} T_{e}^{2}\right)^{j}}
\end{aligned}
$$

The thermal conduction coefficient:

$$
\begin{aligned}
& \mathrm{K}_{\mathrm{e}} \equiv \mu_{\mathrm{e}} \frac{\mathrm{k}^{2} \mathrm{n}_{\mathrm{e}}^{\mathrm{T}} \mathrm{e}}{\mathrm{e}}\left[\frac{1}{\mu_{\mathrm{e}}} \frac{{ }_{\mathrm{e}}}{3 \mathrm{~m}_{\mathrm{e}} \mathrm{n}_{\mathrm{e}}^{2}} \int \mathrm{f}_{\mathrm{e}}^{\mathrm{o}} \mathrm{u}_{\mathrm{e}}^{3} \mathrm{z}_{\mathrm{eb}} \mathrm{d} \vec{v}_{\mathrm{e}}-\mathrm{k}_{\mathrm{e}}^{\mathrm{T}}\left(\frac{5}{2}+\mathrm{k}_{\mathrm{e}}^{\mathrm{T}}\right)\right] \\
& =\frac{8 k^{2}}{3 \Pi^{1 / 2} m_{e}} T_{e} \frac{\sum_{n=0}^{n_{M}} \sum_{k=0}^{n_{M}} k_{n} \hat{x}_{b k}^{(n)}\left(\frac{n_{0}}{n_{e}}\right)^{k}}{\sum_{j=0}^{n_{M}+1} \hat{Y}_{j}\left(\frac{n_{0}}{n_{e}}\right)^{j}}-\mu_{e} k_{e}^{T}\left(\frac{5}{2}+k_{e}^{T}\right) n_{e} T_{e}
\end{aligned}
$$


18

$$
\begin{gathered}
=\frac{8 k^{2}}{3 \Pi^{1 / 2} m_{e}} T_{e} \frac{\sum_{k=0}^{M} \hat{M}_{b k}\left(\frac{n_{0}}{n_{e}}\right)^{k}}{\sum_{j=0}^{n_{M}+1} \hat{Y}_{j}\left(\frac{n_{0}}{n_{e}}\right)^{j}}-\mu_{e} k_{e}^{T}\left(\frac{5}{2}+k_{e}^{T}\right) n_{e}^{T} e \\
=\frac{8 k^{2}}{3 \Pi^{1 / 2} m_{e}} T_{e}^{5 / 2} \frac{\sum_{k=0}^{n_{M}} \hat{⿳}_{b k}\left(\frac{n_{0}}{n_{e}} T_{e}^{2}\right)^{k}}{\sum_{j=0}^{n+1} \hat{\hat{Y}}_{j}\left(\frac{n_{0}}{n_{e}} T_{e}^{2}\right)^{j}}-\mu_{e} k_{e}^{T}\left(\frac{5}{2}+k_{e}^{T}\right) n_{e} T_{e}^{(48)}
\end{gathered}
$$

where:

$$
\begin{aligned}
& c_{n} \equiv \int e^{-u^{2}} u^{4} s_{n}(u) d u \quad\left(C_{n}=0 \text { for } n \neq 0\right) \\
& K_{n} \equiv \int e^{-u^{2}} u^{6} s_{n}(u) d u \quad\left(K_{n}=0 \text { for } n=2\right) \\
& \hat{\mathrm{L}}_{r k} \equiv \sum_{\mathrm{n}} \mathrm{c}_{\mathrm{n}} \hat{\mathrm{x}}_{\mathrm{rk}}^{(\mathrm{n})} \quad \mathrm{r}=\mathrm{a}, \mathrm{b} \\
& \hat{\mathrm{M}}_{\mathrm{rk}} \equiv \sum_{\mathrm{n}} \mathrm{K}_{\mathrm{n}} \hat{\mathrm{X}}_{\mathrm{rk}}^{(\mathrm{n})} \quad \mathrm{r}=\mathrm{b} \\
& \hat{\hat{L}}_{r k} \equiv \sum_{n} C_{n} \hat{\hat{x}}_{r k}^{(n)} \quad r=a, b \\
& \hat{\stackrel{M}{M}}_{r k} \equiv \sum_{n} K_{n} \hat{x}_{r k}^{(n)} \quad r=b \\
& \hat{x}_{r k}^{(n)}=\left(T_{e}^{-3 / 2}\right)^{n_{M}} \hat{\hat{x}}_{r k}^{(n)} \\
& \hat{\mathrm{Y}}_{j}=\left(\mathrm{T}^{-3 / 2}\right)^{\mathrm{n}^{+1}} \hat{\hat{\mathrm{Y}}}_{\mathrm{j}}
\end{aligned}
$$




\section{ELECTRON TRANSPORT COEFFICIENTS OF A CESIUM PLASMA}

Electron transport coefficients for a hard sphere cross section are derived by Wilkins and Gyftopoulos. ${ }^{4}$ In the present paragraph the electron transport coefficients are evaluated for a cesium plasma for an experimantal (Nighan) ${ }^{6}$ and a theoretical (Karule) ${ }^{7}$ electron-neutral cesium elastic cross section. The evaluation is effectuated to the third order approximation thus $n=0,1,2 ; m=0,1,2 ; n_{M}=2$ in $(30)-(51)$. The two functions $z_{e a[3]}^{(n)}$ and $z_{e b[3]}^{(n)}$ corresponding to the general expression (43) are:

$$
\begin{aligned}
& z_{e a[3]}^{(n)}=\frac{\sum_{k=0}^{2} \hat{x}_{a k}^{(n)}\left(\frac{n_{o}}{n_{e}}\right)^{k}}{\sum_{j=0}^{3} \hat{Y}_{j}\left(\frac{n_{0}}{n_{e}}\right)^{j}} \\
& z_{e b[3]}^{(n)}=\frac{\sum_{k=0}^{2} \hat{x}_{b k}^{(n)}\left(\frac{n_{0}}{n_{e}}\right)^{k}}{\sum_{j=0}^{3} \hat{Y}_{j}\left(\frac{n_{o}}{n_{e}}\right)^{j}}
\end{aligned}
$$

where the temperature dependent coefficients are:

$$
\begin{aligned}
& \hat{\mathrm{X}}_{\mathrm{ao}}^{(\mathrm{o})} \equiv(\beta \mathrm{ee})+(\beta \mathrm{ei})+(\beta \mathrm{ie})+(\beta \mathrm{ii}) \\
& \hat{\mathrm{X}}_{\mathrm{a} 1}^{(0)} \equiv(\beta \mathrm{eo})+(\beta \mathrm{io})+(\beta \mathrm{oe})+(\beta \mathrm{oi}) \\
& \hat{\mathrm{X}}_{\mathrm{a} 2}^{(0)} \equiv(\beta \mathrm{oo}) \\
& \hat{\mathrm{X}}_{\mathrm{ao}}^{(1)} \equiv(\mathrm{e} \beta \mathrm{e})+(\mathrm{e} \beta \mathrm{i})+(\mathrm{i} \beta \mathrm{e})+(\mathrm{i} \beta \mathrm{i}) \\
& \hat{\mathrm{X}}_{\mathrm{a} 1}^{(1)} \equiv(\mathrm{e} \beta \mathrm{o})+(\mathrm{i} \beta \mathrm{o})+(\mathrm{o} \beta \mathrm{e})+(\mathrm{o} \beta \mathrm{i}) \\
& \hat{\mathrm{X}}_{\mathrm{a} 2}^{(1)} \equiv(\mathrm{o} \beta \mathrm{o}) \\
& \hat{\mathrm{X}}_{\mathrm{ao}}^{(2)} \equiv(\mathrm{ee} \beta)+(\mathrm{ei} \beta)+(\mathrm{ie} \beta)+(\mathrm{ii} \beta) \\
& \hat{\mathrm{X}}_{\mathrm{a} 1}^{(2)} \equiv(\mathrm{eo} \beta)+(\mathrm{io} \beta)+(\mathrm{oe} \beta)+(\mathrm{oi} \beta) \\
& \hat{\mathrm{X}}_{\mathrm{a} 2}^{(2)} \equiv(\mathrm{oo} \beta) \\
& \mathrm{a})
\end{aligned}
$$


The coefficients $X_{b o}^{(0)}, \ldots . . X_{b 2}^{(2)}$ have similar expressions with $x_{a 0}^{(0)}, \ldots . x_{a 2}^{(2)}$ with the exception that replaces .

$$
\begin{aligned}
& \hat{\mathrm{Y}}_{\mathrm{o}} \equiv(\mathrm{eee})+(\mathrm{eei})+(\mathrm{eie})+(\mathrm{eii})+(\mathrm{iei})+(\mathrm{iie})+(\mathrm{iii})+(\mathrm{iee}) \\
& \hat{\mathrm{Y}}_{1} \equiv(\text { oee })+(\text { oei })+(\text { oie })+(\text { oii })+(\text { eeo })+(\text { eio })+(\text { ieo })+(\text { iio }) \\
& +(\text { eoe })+(\text { eoi })+(\text { ioe })+(\text { ioi }) \\
& \hat{\mathrm{Y}}_{2} \equiv(\mathrm{eoo})+(\mathrm{ioo})+(\mathrm{oeo})+(\mathrm{oio})+(\text { ooe })+(\text { ooi }) \\
& \hat{\mathrm{Y}}_{3} \equiv(000)
\end{aligned}
$$

The following notation is used:

$$
\begin{aligned}
(\xi \eta \zeta) \equiv & \hat{\delta}_{\xi} 00 \hat{\delta} \eta 11 \hat{\delta}_{\zeta} 22+\hat{\delta}_{\xi} 10 \hat{\delta}_{\eta} 21 \hat{\delta}_{\zeta} 02+\hat{\delta}_{\xi} 20 \hat{\delta}_{\eta} 01 \hat{\delta}_{\zeta} 12 \\
& -\hat{\delta}_{\xi} 20 \hat{\delta}_{\eta} 11 \hat{\delta}_{\zeta} 02-\hat{\delta}_{\xi} 00 \hat{\delta}_{\eta} 21 \hat{\delta}_{\zeta} 12-\hat{\delta}_{\xi} 10 \hat{\delta}_{\eta} 01 \hat{\delta}_{\zeta} 22
\end{aligned}
$$

together with:

$$
\hat{\delta}_{\varphi} \mathrm{mn} \equiv \begin{cases}\hat{\delta}_{\mathrm{e}, \mathrm{e} \varphi}^{(\mathrm{m}, \mathrm{n})} & \varphi \neq \beta, \gamma \\ \beta^{\mathrm{m}} & \varphi=\beta \\ \gamma^{\mathrm{m}} & \varphi=\gamma\end{cases}
$$

Expressions for $\beta^{\mathrm{m}}, \gamma^{\mathrm{m}}$ are given in (3) and are adimensional.

The resulting transport coefficients defined in (46) - (48) and in the additional relations (49- (51), are evaluated as follows:

$$
\mu_{e[3]}=\frac{8 e}{3 \pi / 2 n_{e} m_{e}} \frac{\hat{L}_{a o}+\hat{L}_{a i} \frac{n_{0}}{n_{e}}+\hat{L}_{a 2}\left(\frac{n_{0}}{n_{e}}\right)^{2}}{\hat{Y}_{o}+\hat{Y}_{1} \frac{n_{0}}{n_{e}}+\hat{Y}_{2}\left(\frac{n_{0}}{n_{e}}\right)^{2}+\hat{Y}_{3}\left(\frac{n_{0}}{n_{e}}\right)^{3}}
$$


21

$$
\begin{aligned}
& \frac{\hat{L}_{b o}+\hat{L}_{b 1} \frac{n_{o}}{n_{e}}+\hat{L}_{b 2}\left(\frac{n_{o}}{n_{e}}\right)^{2}}{+\hat{Y}_{1} \frac{n_{o}}{n_{e}}+\hat{Y}_{2}\left(\frac{n_{o}}{n_{e}}\right)^{2}+\hat{Y}_{3}\left(\frac{n_{o}}{n_{e}}\right)^{3}} \\
& k_{e[3]}^{T}=\frac{1}{\mu_{e}} \cdot \frac{8 e}{3 \pi^{1 / 2} n_{e} m_{e}} \\
& \mathrm{~K}_{\mathrm{e}[3]}=\mu_{\mathrm{e}} \frac{{ }_{\mathrm{e}} \mathrm{e}^{2} \mathrm{~T}_{\mathrm{e}}}{\mathrm{e}} \frac{1}{\mu_{\mathrm{e}}} \frac{8 \mathrm{e}}{3 \pi^{1 / 2} \mathrm{n}_{\mathrm{e}} \mathrm{m}_{\mathrm{e}}} \\
& \hat{M}_{b o}+\hat{M}_{b 1} \frac{n_{o}}{n_{e}}+M_{b 2}\left(\frac{n_{0}}{n_{e}}\right)^{2}
\end{aligned}
$$

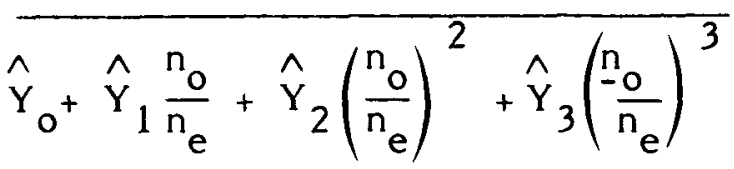

$$
\begin{aligned}
& -k_{e}^{T}\left(\frac{5}{2}+k_{e}^{T}\right)
\end{aligned}
$$

where according to (50) and (49):

$$
\begin{aligned}
& \hat{\mathrm{L}}_{\mathrm{rk}}=\mathrm{C}_{\mathrm{o}} \hat{\mathrm{X}}_{\mathrm{rk}}^{(0)} \quad\left(\mathrm{C}_{\mathrm{n}}=0 \quad \text { for } \mathrm{n} \neq\right)^{0} \\
& \hat{\mathrm{M}}_{\mathrm{rk}}=\mathrm{K}_{0} \hat{\mathrm{X}}_{\mathrm{rk}}^{(0)}+\mathrm{K}_{1} \cdot \hat{\mathrm{X}}_{\mathrm{rk}}^{(1)} \quad\left(\mathrm{K}_{2}=0\right)
\end{aligned}
$$

They are completely determined by the set of 13 independent coefficients $\hat{\mathrm{L}}_{\text {no }}, \ldots . . \widehat{\mathrm{Y}}_{3}$ which are given on Fig. 1 and Table 1 as function of temperature for the best guess and theoretical cross sections indicated on Fig. 2.

As indicated in the preceding paragraph, and as results from expressions (49) - (50), for a hard sphere cross section the 13 coefficients in (58) (60) are by definition independent of density and depend on temperature as follows:

$$
\begin{array}{ll}
\hat{\mathrm{L}}_{\mathrm{ak}}^{\mathrm{HS}}=\left(\mathrm{T}^{-3 / 2}\right)^{2}\left(\mathrm{~T}^{2}\right)^{\mathrm{k}} \hat{\hat{\mathrm{L}}}_{\mathrm{ak}}^{\mathrm{HS}} & \partial \hat{\hat{\mathrm{L}}}_{\mathrm{HS}} / \partial \mathrm{T}=0 \\
\hat{\mathrm{L}}_{\mathrm{bk}}^{\mathrm{HS}}=\left(\mathrm{T}^{-3 / 2}\right)^{2}\left(\mathrm{~T}^{2}\right)^{\mathrm{k}} \hat{\hat{\mathrm{L}}}_{\mathrm{bk}}^{\mathrm{HS}} & \partial \hat{\hat{\mathrm{M}}}_{\mathrm{HS}}^{\mathrm{HS}} / \partial \mathrm{T}=0 \\
\hat{\mathrm{M}}_{\mathrm{bk}}^{\mathrm{HS}}=\left(\mathrm{T}^{-3 / 2}\right)^{2}\left(\mathrm{~T}^{2}\right)^{\mathrm{k}} \hat{\hat{\mathrm{M}}}_{\mathrm{bk}}^{\mathrm{HS}} & \\
\hat{\mathrm{Y}}_{\mathrm{HS}}^{\mathrm{HS}}=\left(\mathrm{T}^{-3 / 2}\right)^{3}\left(\mathrm{~T}^{2}\right)^{\mathrm{k}} \hat{\hat{\mathrm{Y}}}_{\mathrm{HS}} & \partial \hat{\hat{\mathrm{Y}}}_{\mathrm{HS}}^{\mathrm{HS}} / \partial \mathrm{T}=0
\end{array}
$$


It is sometimes interesting to find out what influence the electron-neutral elastic cross section has on the mobility. As even a second order approximation expansion of the functions $\vec{z}_{\mathrm{e}, \mathrm{r}}$ in (2) gives satisfactory results for the mobility, it is sufficient for this purpose to evaluate $z_{e, a[2]}^{0}$ and $z_{e, a[2]}^{1}$ from (1) which yields:

$$
\begin{aligned}
& z_{\mathrm{e}, \mathrm{a}[2]}^{0}=\frac{\beta^{0} \delta^{11}}{\delta^{00} \delta^{11}-\delta^{10} \delta^{01}} \\
& z_{\mathrm{e}, \mathrm{a}[2]}^{1}=\frac{\beta^{0} \delta^{10}}{\delta^{00} \delta^{11}-\delta^{10} \delta^{01}}
\end{aligned}
$$

and to use the poligonal approximation of the cross section expressed in (27) and the integrals expressed in (30) in order to evaluate $\delta_{e, e o}$ from (28), (35), (39), (40) and thus $Z_{\text {ea }}$ from (2) and the mobility from (46). The resulting mobility is an explicit expression of densities, temperature and slopes of the cross section.

The transport coefficients expressed in (58) - (60) depend primarily on the three independent parameters $\mathrm{n}_{\mathrm{e}}, \mathrm{n}_{\mathrm{o}}, \mathrm{T}_{\mathrm{e}}$. They are represented on Fig. 3 versus electron temperature $500^{\circ} \mathrm{K} \leq \mathrm{T}_{\mathrm{e}} \leq 3500^{\circ} \mathrm{K}$ for fixed values of the electron and neutral particle density $\left(\mathrm{n}_{\mathrm{o}}=8 \times 10^{15} \mathrm{~cm}^{-3}, \mathrm{n}_{\mathrm{e}}=8 \times 10^{13} \mathrm{~cm}^{-3}\right)$. In particular the electron mobility in (58) varies as follows:

$$
\mu_{e} n_{e}=f\left(\frac{n_{o}}{n_{e}}, T_{e}\right)
$$

thus at each $T_{e}$ on Fig. 3 and for $n_{o} n_{e}=10^{2}$ the mobility scales as $1 n_{e}$.

The actual distribution of densities and temperatures in a real converter results from conservation equations solution and clearly, due to the spatial inhomogeneities and lack of interspecies thermalization maintained by the boundary fluxes, their values cannot be predicted by equilibrium equations as perfect gas and Saha. Figure 4 shows how the set of variables chosen as input for the results presented on Fig. 3 differ from the perfect gas and Saha predictions. The solution of 
the transport coefficients versus distance from emitter in a thermionic converter is presented on Fig. 5, based on an example of integrated plasma parameters provided by Dr. C. C. Wang and shown on Fig. 6 .

\section{ELECTRON TRANSPORT AND PLASMA RESISTANCE IN TYPICAL THERMIONIC CONVERTER CONDITIONS}

The electron particle and heat flux result directly from their definitions, once the transport coefficients are known:

$$
\begin{aligned}
& \vec{J}_{e} \equiv e \int \vec{v}_{e} f_{e} d \vec{v}_{e}=-\mu_{e}\left(\operatorname{grad} p_{e}+e e_{e} \vec{E}+k_{e}^{T} n_{e} k \operatorname{grad} T_{e}\right) \\
& \vec{q}_{e} \equiv \frac{m v_{e}^{2}}{2} \vec{v}_{e} f_{e} d \vec{v}_{e}=\frac{J_{e}}{e} \frac{5}{2} k T_{e}+\frac{J_{e}}{e} k_{e}^{T} k T_{e}-K_{e} \operatorname{grad} T_{e}
\end{aligned}
$$

They depend on transport coefficients and on gradients of the electron pressure, temperature and electrostatic potential and are illustrated on Fig. 7 as function of the distance from-the emitter for the conditions shown on Fig. 6. As seen on Fig. 7 there are two main contributions to the electron current density, one attributed to the pressure gradient, the second attributed to the electric field.

The plasma resistivity is related to the conductivity as follows:

$$
\rho_{\mathrm{e}}=1 / \mu_{\mathrm{e}} \mathrm{en}_{\mathrm{e}}
$$

and is represented on Fig. 8 for the same conditions described on Fig. 6. Its spatial variation is determined by the spatial variation of the product electron mobility times electron number density which results from expression (58). The negative effect of the neutral cesium atom to the electron passage through the plasma may be isolated by evaluating the mobility in the presence of neutrals, $\mathrm{n}_{0} \neq 0$, and in their absence, $\mathrm{n}_{0}=0$, in expression (58). The resistivity in the absence of neutrals is due to the electron-electron and electron-ion long range electrostatic interactions, and the values shown on Fig. 8 coincide within interpolation errors with the values obtained by Spitzer. ${ }^{8}$ 


$$
\text { At } \mathrm{T}_{\mathrm{e}}=3000^{\circ} \mathrm{K} \quad\left(\rho_{\mathrm{e}}\right) \mathrm{n}_{\mathrm{o}} \neq 0 /\left(\rho_{\mathrm{e}}\right)_{\mathrm{n}_{\mathrm{o}}=0}=3.667
$$

and at $\mathrm{T}_{\mathrm{e}}=2500^{\circ} \mathrm{K}\left(\rho_{\mathrm{e}}\right)_{\mathrm{n}_{\mathrm{o}}} \neq \rho\left(\rho_{\mathrm{e}}\right)_{\mathrm{n}_{\mathrm{o}}=0}=2.4$

The resistivity of a fully ionized gas is given in order to serve as reference to the resistivity of a partly ionized gas, and it does not mean that in converter conditions a fully ionized gas can exist at the considered temperatures.

\section{CONCLUSIONS}

The electron transport coefficients in a cesium plasma are expressed analytically as function of density and temperature dependent coefficients which are numerically tabulated as function of temperature for an experimental and a theoretical electron-neutral elastic cross section. They are used to evaluate the plasma resistance to the electron transport across it. According to (62) and (64), for given gradient of electron pressure, electron density and electric field, the resistivity determines the electron current density and also influences the current indirectly through its effect on pressure and electric field. It reflects the interaction of the electrons with various species (ions or neutrals) and evidences their individual influence on the electron current density. Setting $n_{0}=0$ in Eqs. (58) - (60) leads to the transport coefficients in the absence of neutrals and shows how much penalty one has to pay in electron current resulting from the cesium presence in the interelectrode distance, for the advantage of lowering the cathodes work function through cesium adsorbtion and on the surface.

For given boundary conditions at the electrodes, interelectrode spacing and pressure, the solution of the transport equations and Poisson equation which yields the spatial distribution of the density, electric current, temperature and electric field, is unique. The optimum thermionic converter is the one which has the lowest 
internal voltage drop defined as the work done by a unit charge to cross the interelectrode spacing, which is equal to the line integral of the electric field. This optimum is therefore reached by varying the interelectrode spacing, pressure and physical boundary surface conditions. Improving the converter performance beyond the optimum obtained as described above, rests therefore on the capability of altering physical conditions which are reflected in terms of the conservation equations and Poisson equation, as, for instance additional ionization rate, or as additional boundary conditions generated by supplementary electrodes.

In any case an accurate solution of transport equations is needed in order to analyze the physical model and seek beneficial solutions. The transport coefficients treated in the present work make possible a more accurate integration of transport equations at a given level of computational complexity.

There are two main difficulties encountered in the mathematical modeling of a converter. One is related to the fact that one cannot discriminate experimentally the electrode work function from the internal voltage drop, as the work function in converter operation conditions which produce cesium adsorbed layers on the electrodes, is inaccessible to experiments. The second is a result of the invalidity of the transport equations in the sheaths regions neighboring the electrodes due to the assumption of close to equilibrium (Maxwellian) velocity distribution functions, which is implicit in the expressions of the transport coefficients. The present effort helps to analyze the contribution of the plasma region described properly by transport equations, to the converter performance. A complementary effort is felt necessary to analyze the sheaths and the electrode work function in converter operating conditions. 


\section{ACKNOWLEDGMENTS}

The authors gratefully acknowledge the contribution of Timothy M. Smith and Stephen R. Channon to the Coulomb collisions evaluation. 


\section{REFERENCES}

1. D. Enskog, Kinetische Theorie der Vorgänge in mä $\beta$ ig verdünnten Gasen, Tuaugural Dissertation, Uppsala (1917).

2. S. Chapman and T. G. Cowling, The Mathematical Theory of Non-Uniform Gases, Cambridge Univ. Press (1939).

3. J. O. Hirschfelder, C. F. Curtiss, R. B. Bird, Molecular Theory of Gases and Liquids, John Wiley \& Sons, (1954).

4. D. R. Wilkins and E. P. Gyftopoulos, Transport Phenomena in Low Energy Plasmas, J. Appl. Phys., 37, 3533 - 3540 (1966).

5. B. A. Trubnikov in Reviews of Plasma Physics, Consultants Bureau Enterprises, Inc., 1965.

6. W. L. Nighan, Physics of Fluids, 10, 1085 (1967).

7. E. Karule, "The Spin Polarization and Differential Cross Sections in the Elastic Scattering of Electrons by Alkali Metal Atoms," J. Phys. B: Atom. Molec. Phys., 5, 2051-2060 (1972).

8. L. Spitzer, Physics of Fully Ionized Gases, Interscience Publishers, John Wiley \& Sons (1962). 

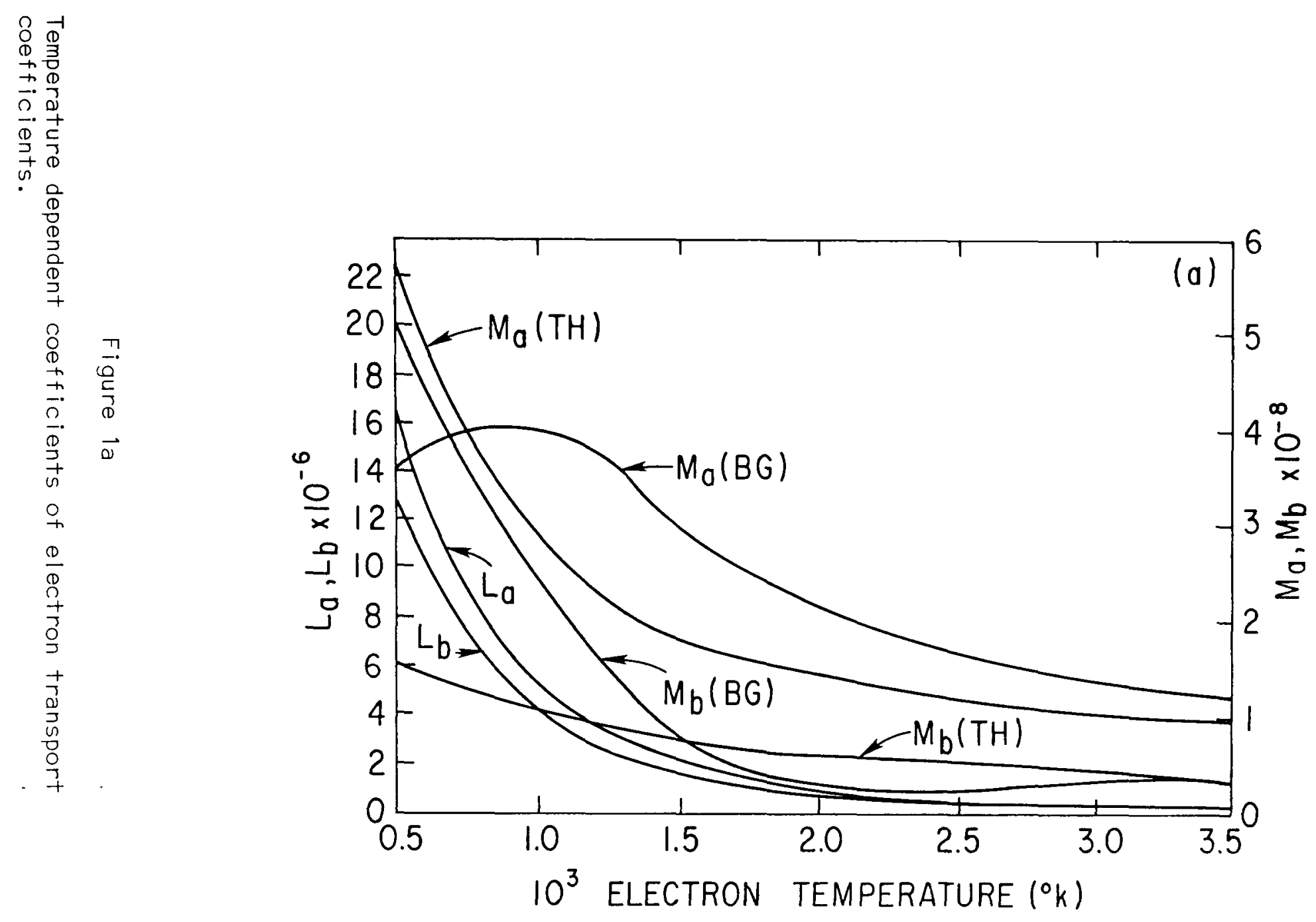

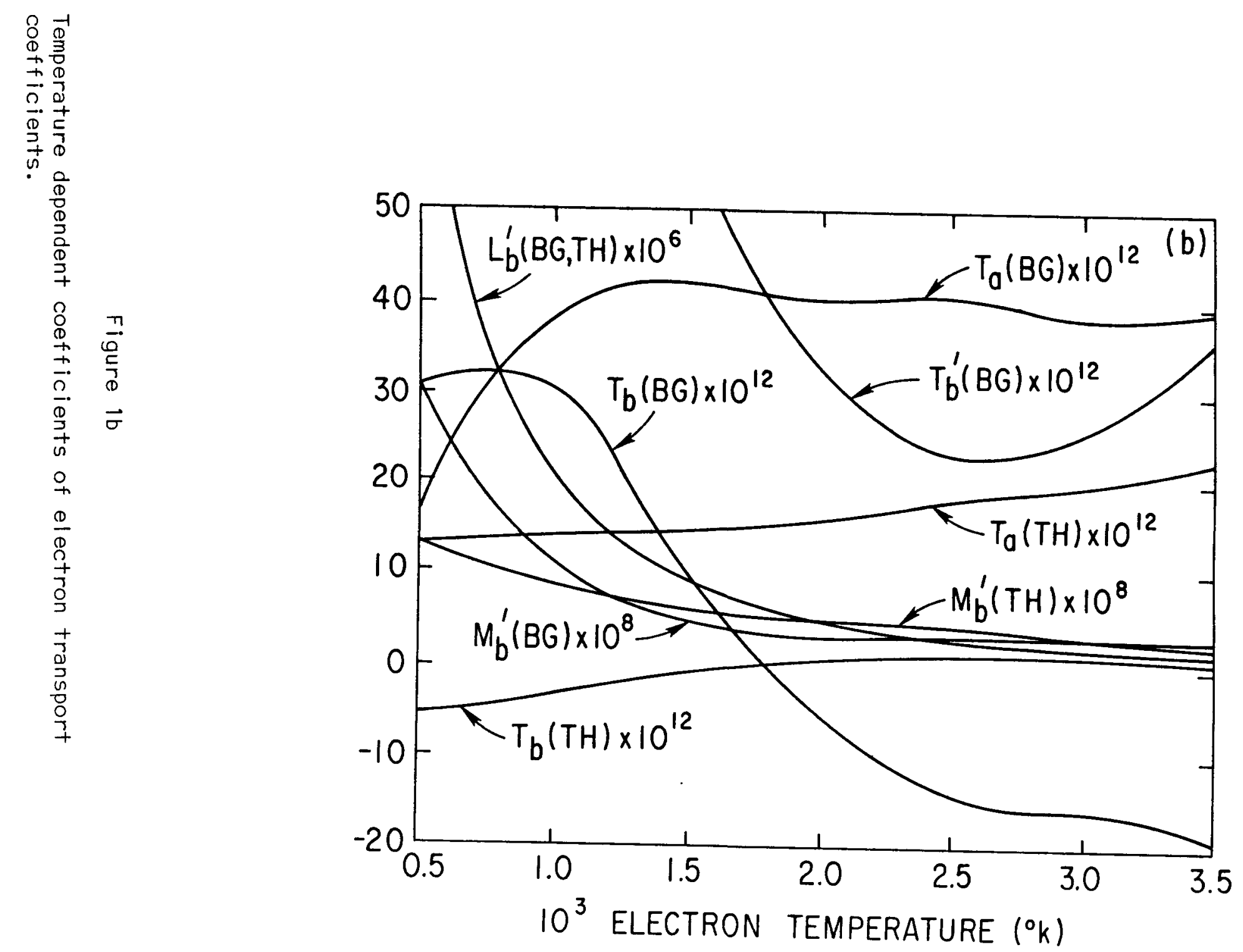

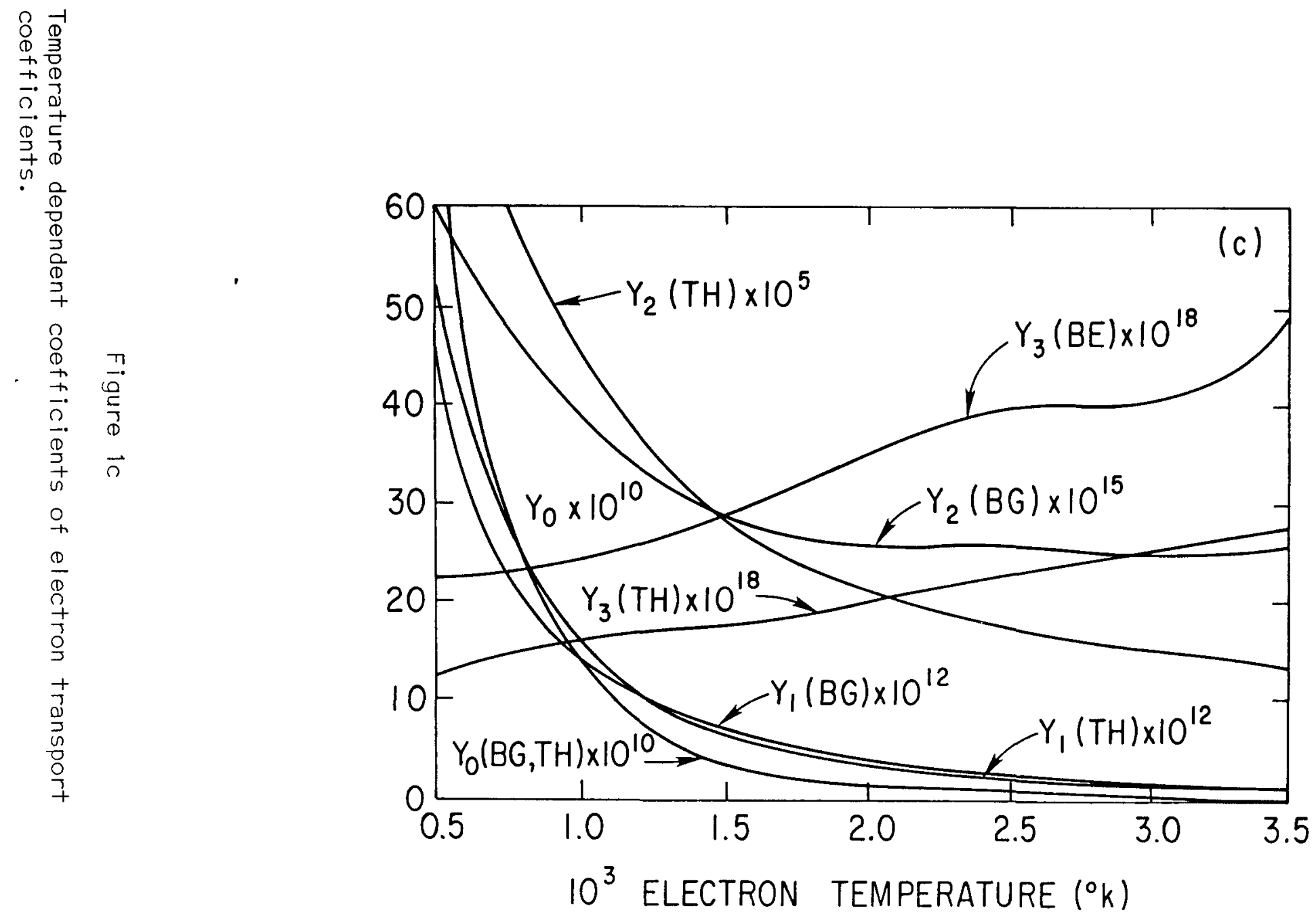

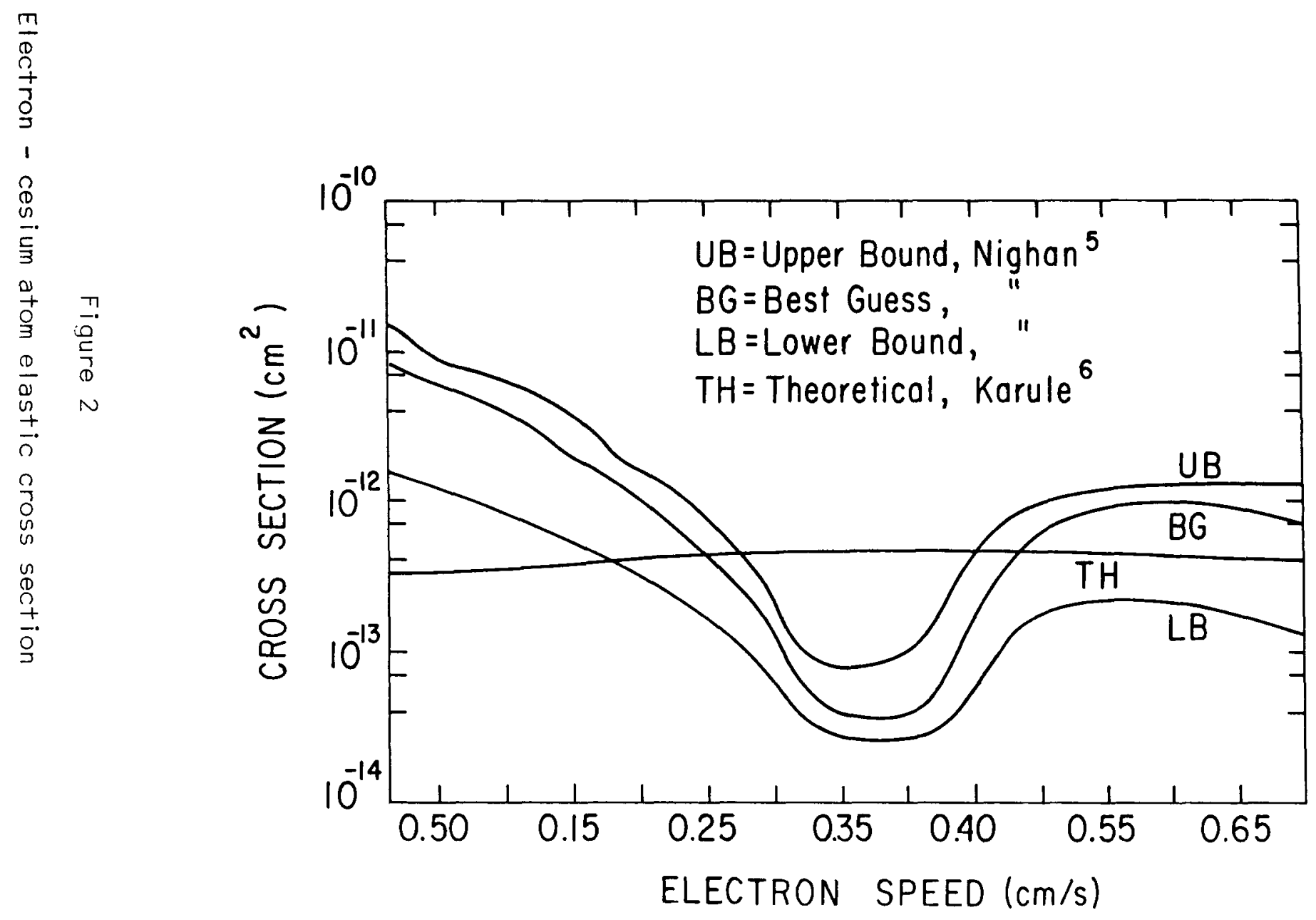

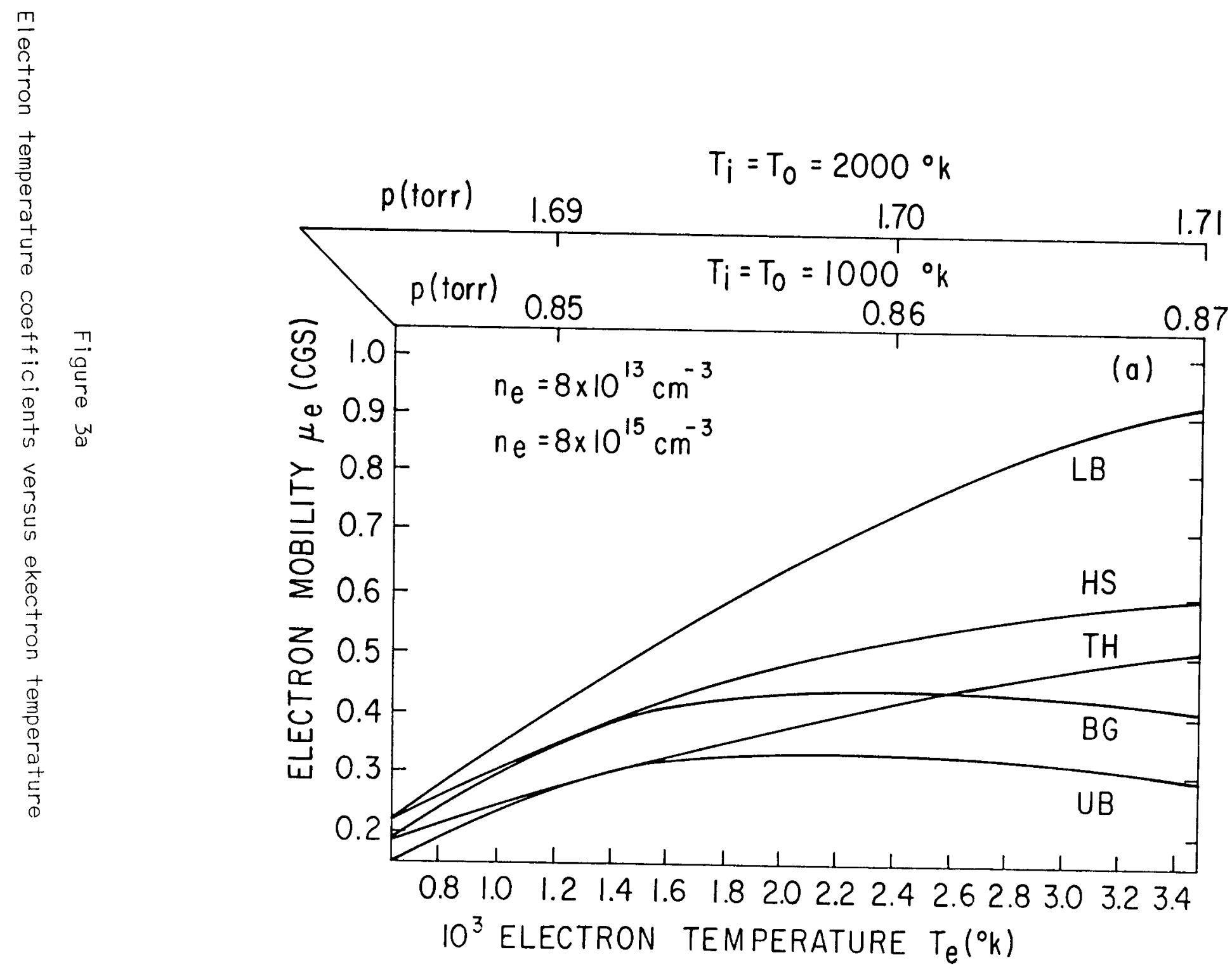

$\underline{N}$ 

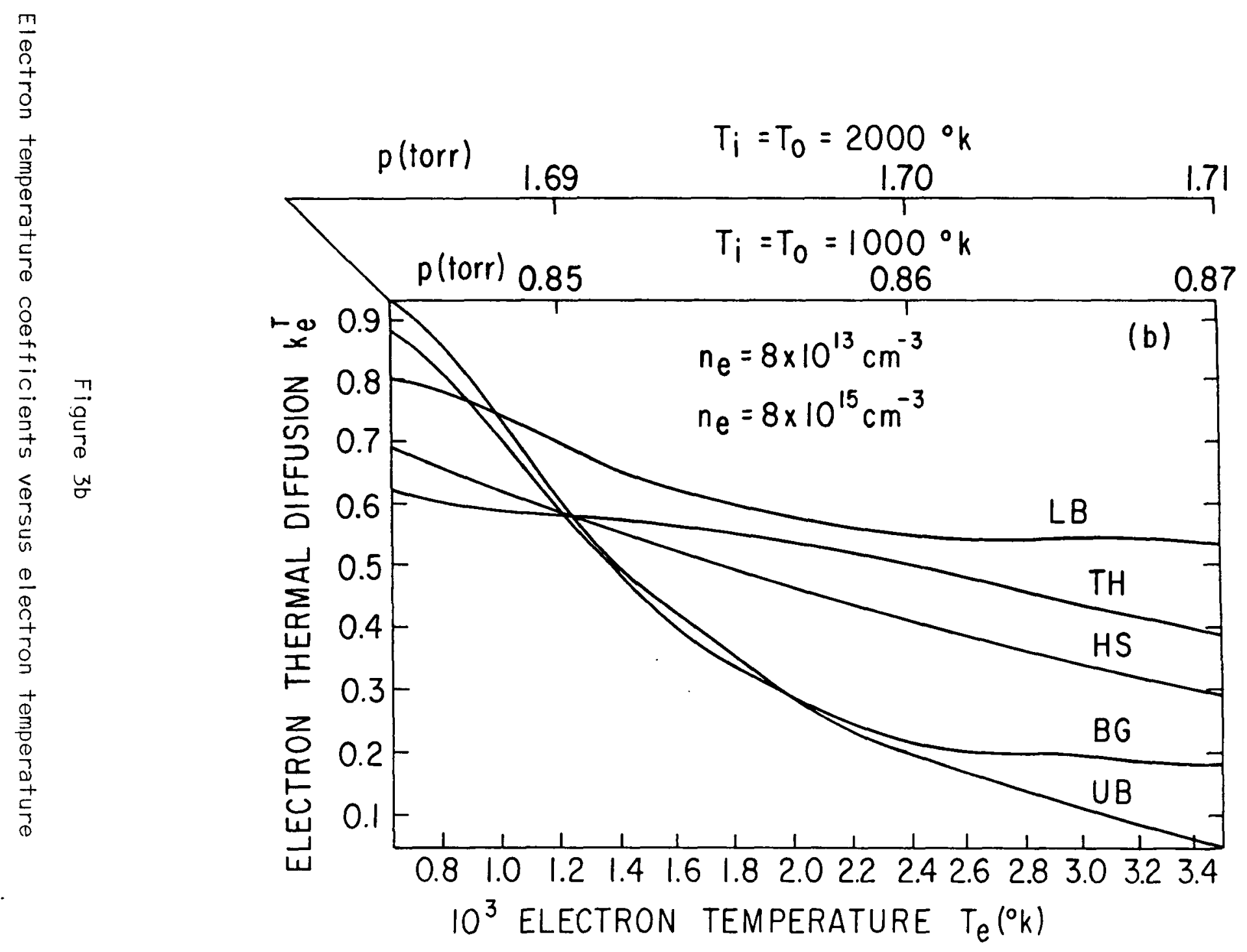

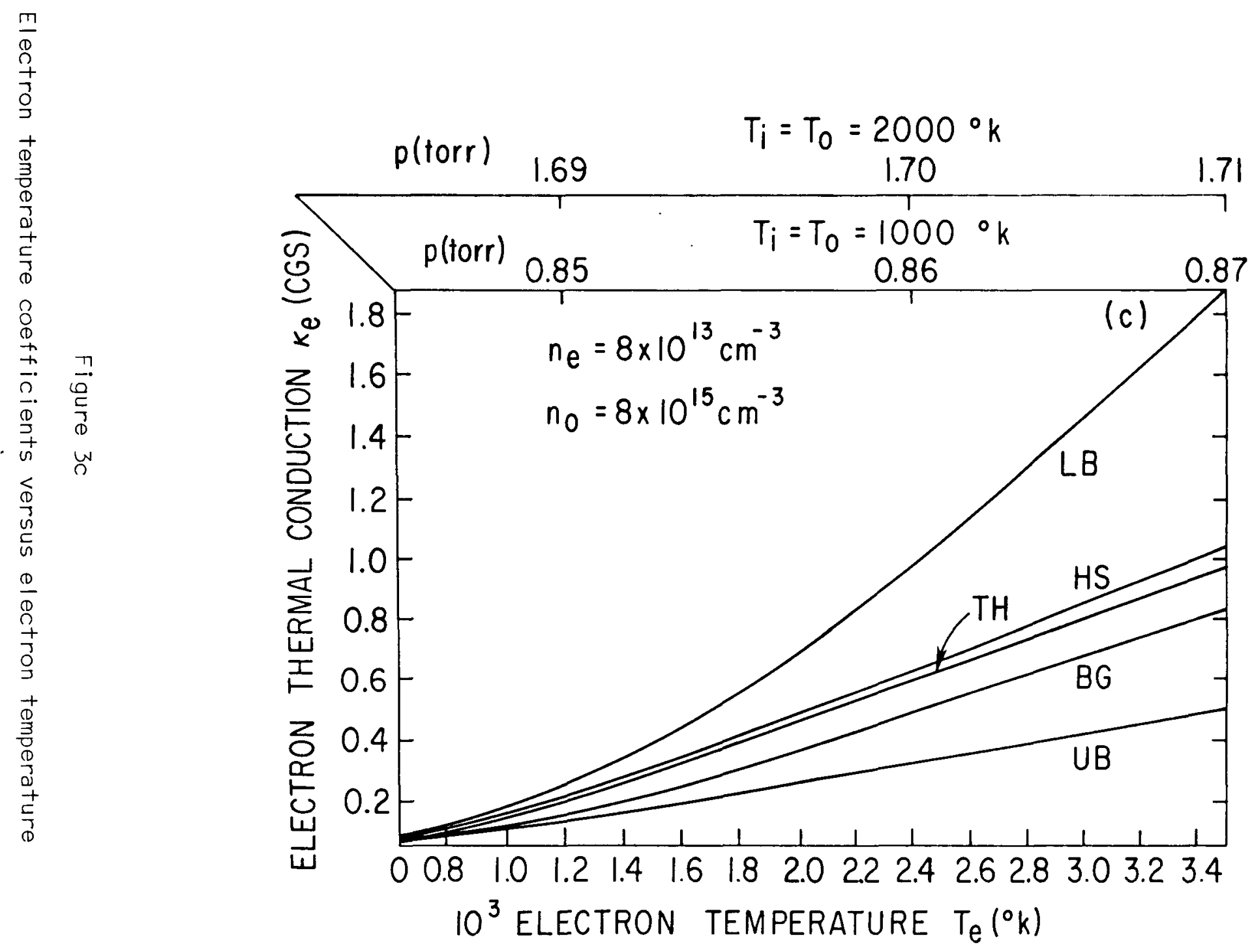

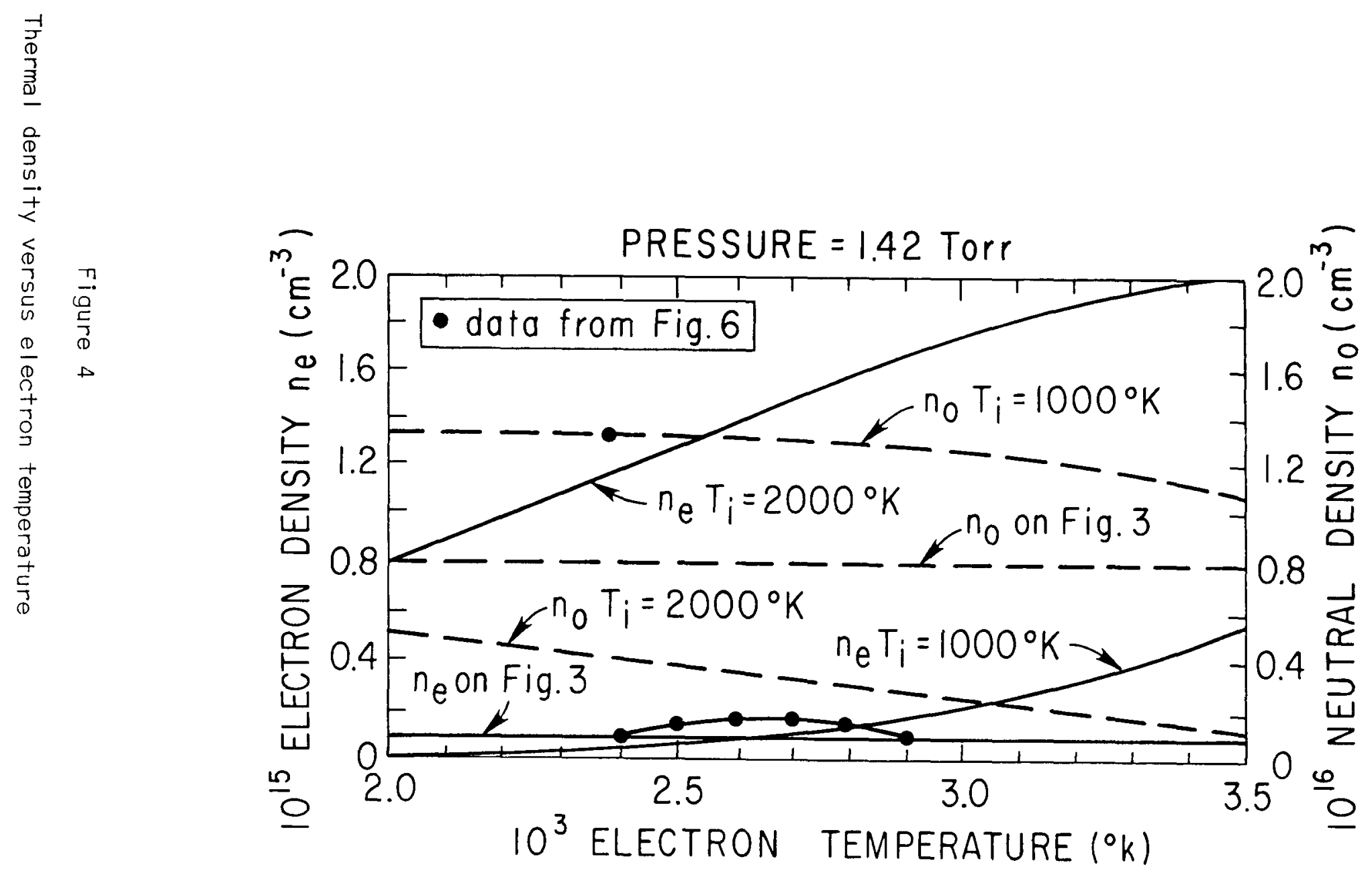

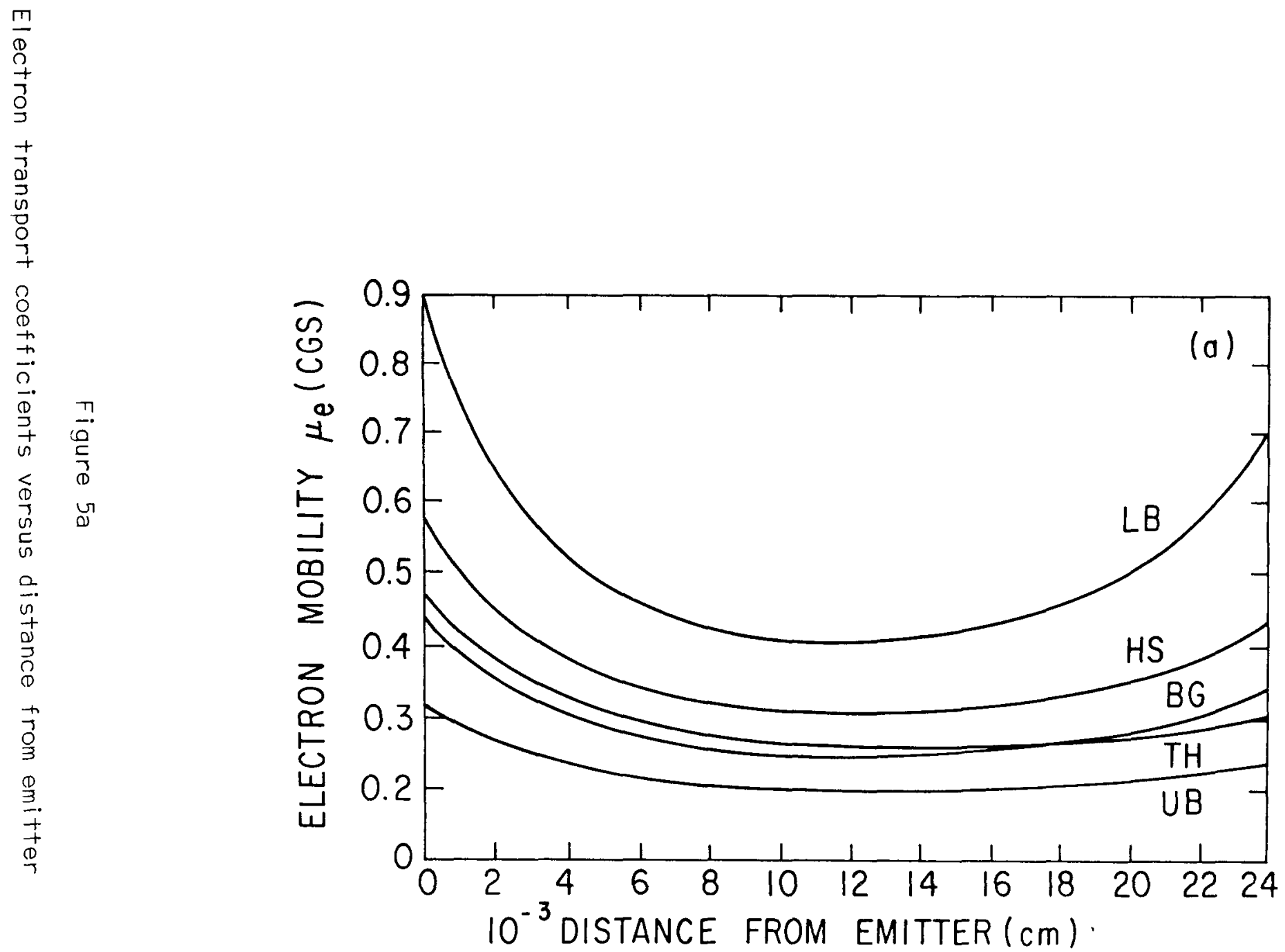

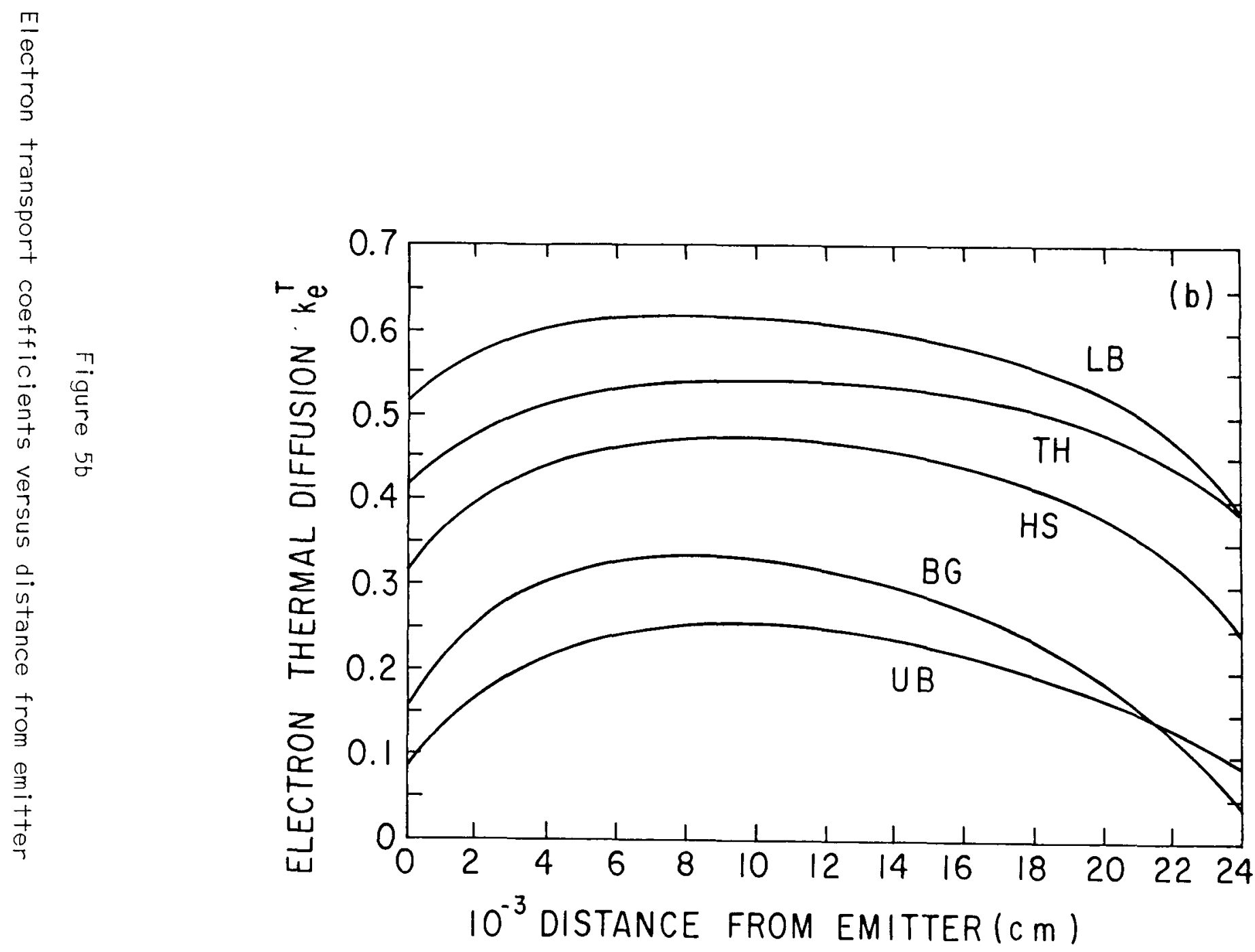

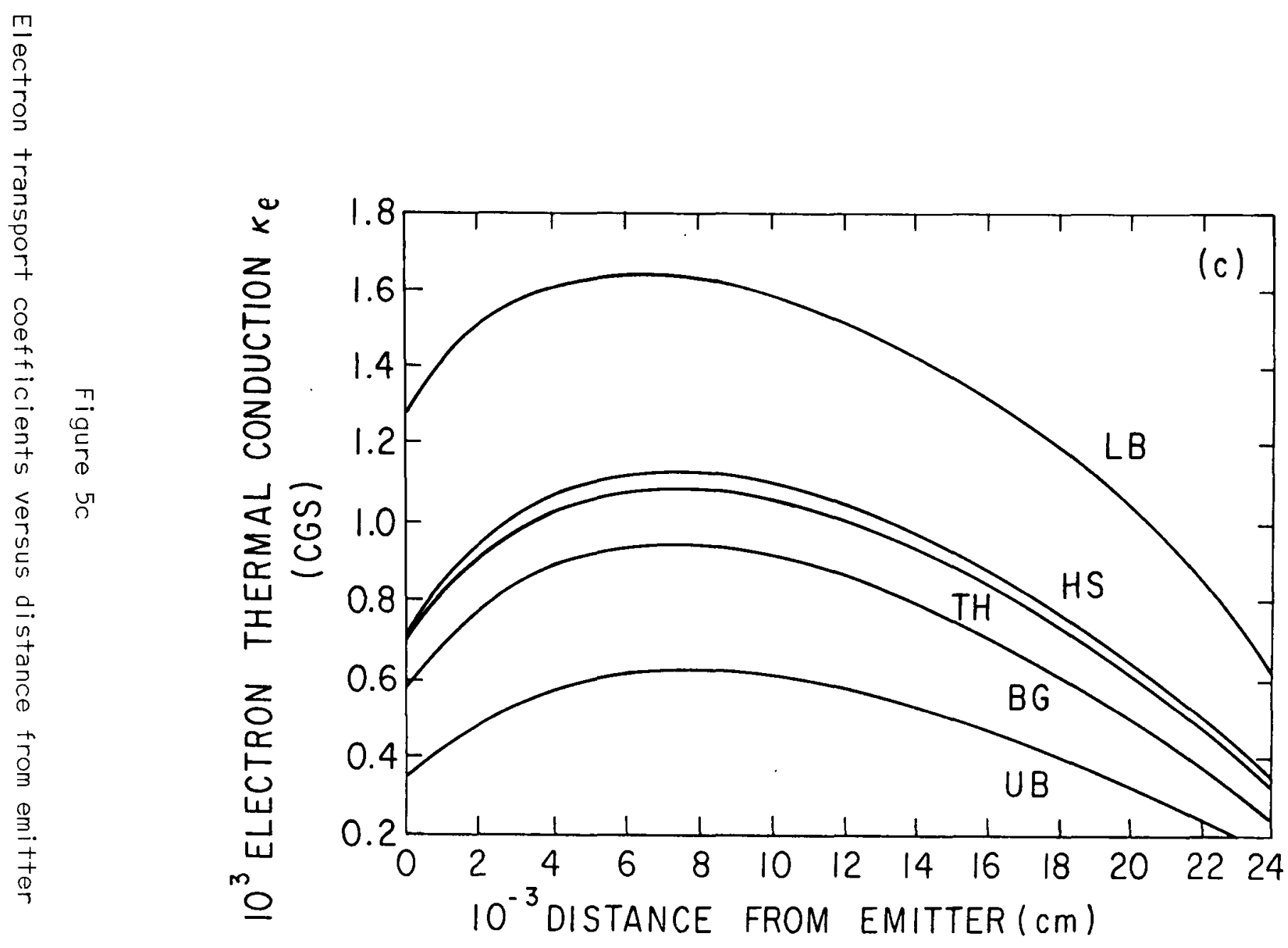

$\underset{\infty}{w}$ 


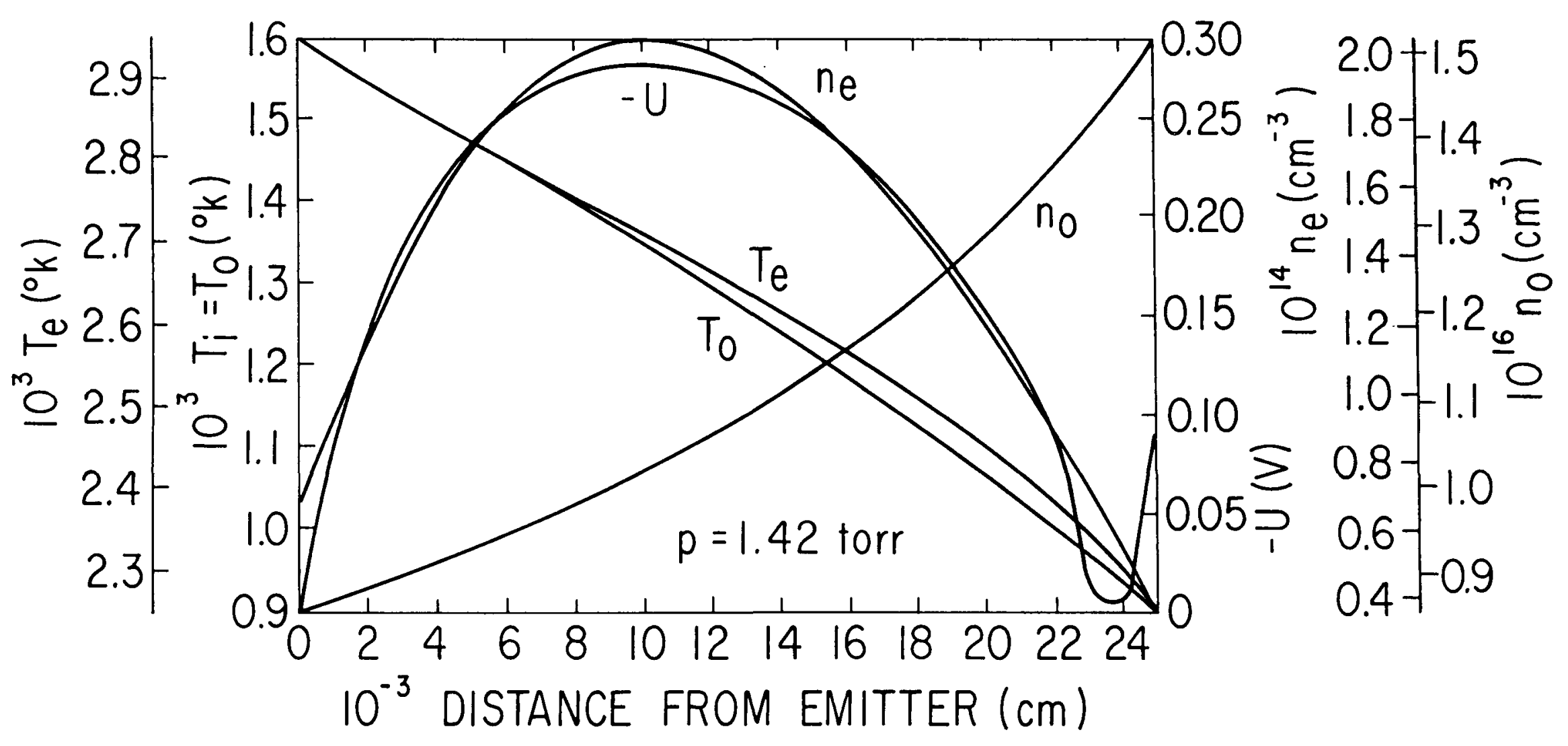



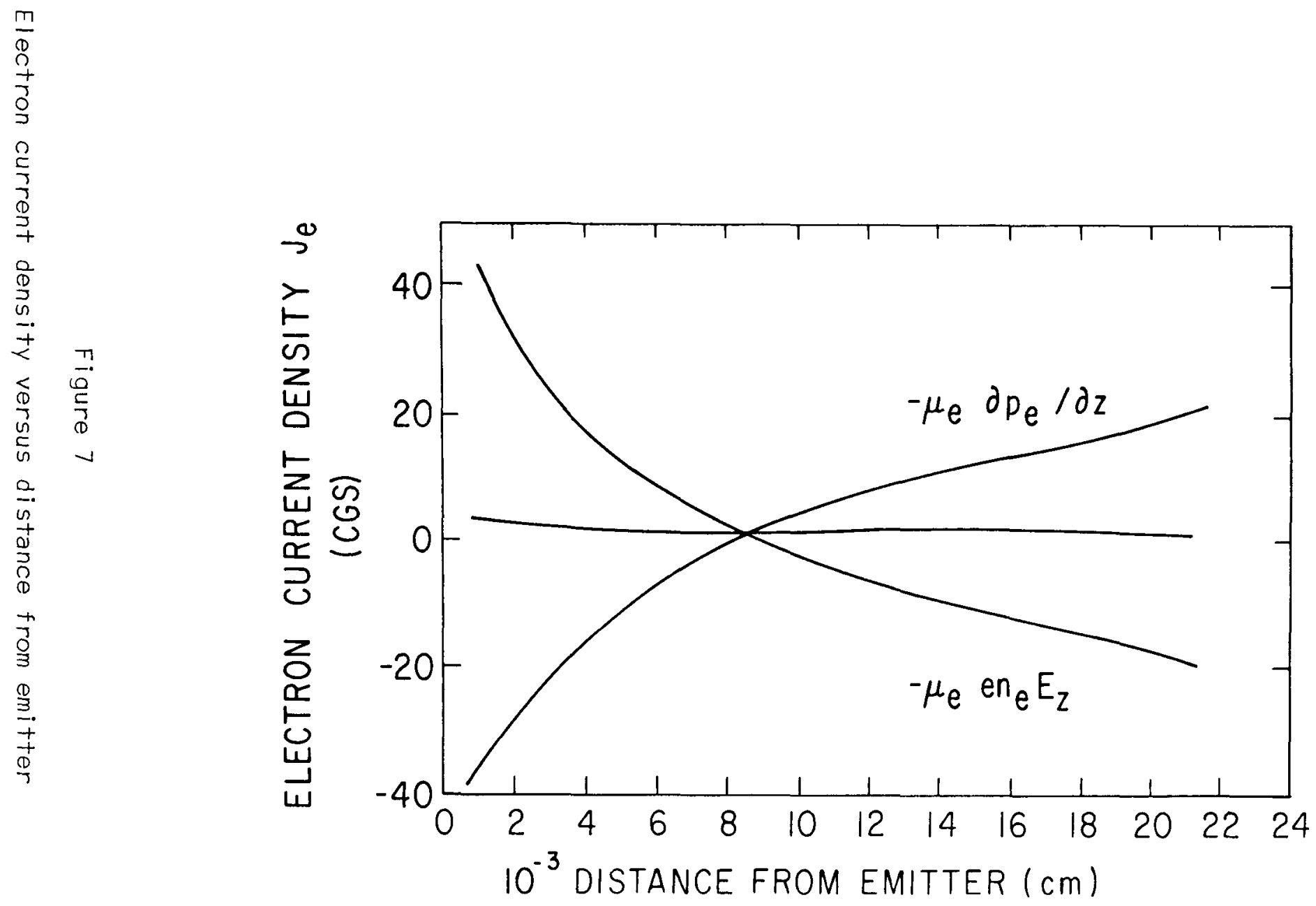

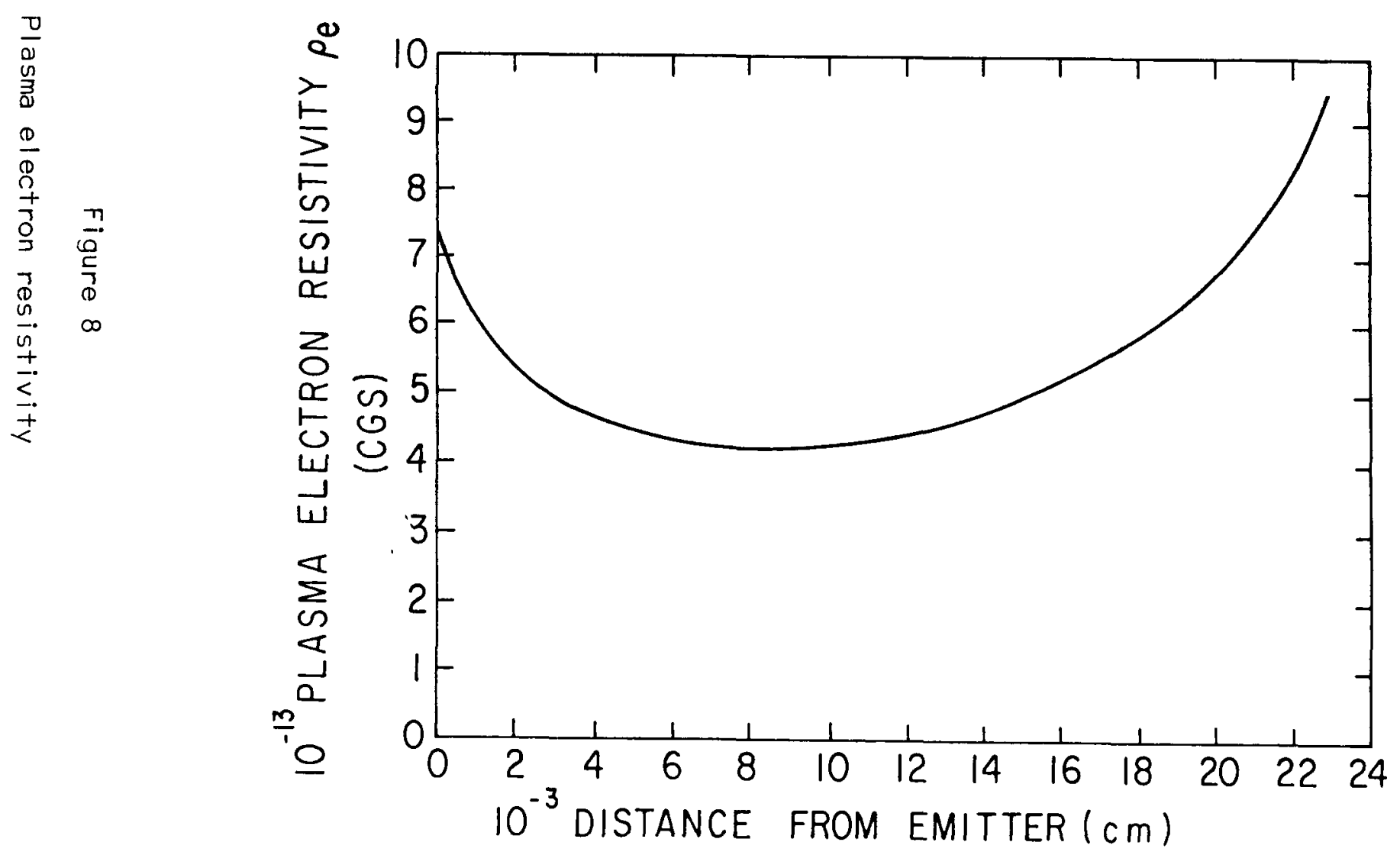


\section{ALL CATEGORIES}

R. Askew, Auburn University, Alabama

S. T. Wu, Univ. of Alabama

Geophysical Institute, Univ. of Alaska

G.L. Johnston, Sonoma St ate Univ, Cal ifornia

H. H. Kuehl, Univ. of S. Cal if ornia

Institute for Energy Studies, Stanf ord University

H. D. Campbell, Uni versity of Florida

N. L. Oleson, University of South Florida

W. M. Stacey, Georgia Institute of Technology

Benjamin Ma, lowa State University

Magne Kristiansen, Texas T ech. Uni versity

W. L. Wiese, Nat'l Bureau of Standar ds, Wash., D.C.

Australian National University, Canberra

C.N. Watson-Munro, Univ. of Sydney, Australia

F. Cap, Inst. for Theo. Physics, Austria

Dr.M. Heindler, Institute for Theoretical Physics

Technical University of Graz

Ecole Royale Militaire, Bruxelles, Bel gium

D. Pal um bo, C. European Comm. B-1049-Brussel s

P.H. Sakanaka, Instituto de Fisica, Campinas, Brazil

M.P. Bachynski, MPB Tech., Ste. Anne de Bellevue,

Quebec, Canada

C. R. James, University of Alberta, Canada

T.W. Johnston, INRS-Energie, Vareenes, Quebec

H. M. Skarsgard, Uni v. of Saskatchewan, Canada

Inst. of Physics, Academia Sinica, Peking,

People's Republic of China

Inst. of Plasma Physics, Hefei,

Anhwei Province, People's Republic of China

Library, T sing Hua Univ., Peking, People's

Republic of China

Zhengwu Li, Southwestern Inst. of Phys., Leshan, Sichuan Province, People's Republic of China Librarian, Culham Laboratory, Abingdon, England

A.M. Dupas Library, C.E.N.-G, Grenoble, France

Central Res. Inst. for Physics, Hungary

S. R. Sharma, Univ. of Rajasthan, JAIPUR-4, India

R. Shingal, Meer ut College, India

A.K. Sundaram, Phys. Res. Lab., India

Biblioteca, Frascati, Italy

Biblioteca, Milano, It aly

G. Rostagni, Univ. Di Padova, Padova, Italy

Preprint Library, Inst. de Fisica, Pisa, It aly

Library, Plasma Physics Lab., Gokas ho, Uji, Japan

S. Mori, Japan A tomic Energy Res. Inst.,Tokai-Mura

Resear ch Inf ormation Center, Nago ya Univ., Japan

S. Shioda, Tokyo Inst. of Tech., Japan

Inst. of Space \& Aero. Sci., Univ. of Tokyo

T. Uchida, Univ. of Tokyo, Japan

H. Y amato, Toshiba R. \& D. Center, Japan

M. Yoshikawa, JAERI, Tokai Res. Est., Japan

Dr. Tsuneo Nakakita, Toshiba Corporation,

Kawasaki-Ku Kawasaki, 210 Japan

N. Y ajima, Kyus hu Univ., Japan

R. England, Univ. Nacional Auto-noma de Mexico

B. S. Liley, Univ. of Waikato, New Zealand

S. A. Moss, Saab Univas Norge, Norway

J.A.C. Cabral, Univ. de Lisboa, Port ugal

O. Petrus, AL.I, CUZA Univ., Romania

J. de Villiers, Atomic Energy Bd., South Africa

A. Maurech, Comisaria De La Energy y Recoursos Minerales, Spain

Library, Royal Institute of Technology, Sweden

Cen. de Res. En Phys.Des Plasmas, Switzerland

Librarian, Fom-Instituut Voor Plasma-F ysica,

The Netherlands
Bibliothek, Stuttgart, West Germany

R.D. Buhler, Univ. of Stuttgart, West Germany

Max-Planck-Inst. fur Plasmaphysik, W. Germany

Nucl. Res. Estab., Julich, West Germany

K. Schindler, Inst. Fur Theo. Physik, W. Germany

\section{EXPERIMENTAL THEORETICAL}

M. H. Brennan, Flinders Univ. Australia

H. Barnard, Univ. of British Columbia, Canada

S. Screenivasan, Univ. of Calgary, Canada

J. Radet, C.E.N.-B.P., Font enay-aux-Roses, France

Prof. Schatzman, Obser vatoire de Nice, France

S. C. Sharma, Univ. of Cape Coast, Ghana

R. N. Aiyer, Laser Section, India

B. Buti, Physical Res. Lab., India

L. K. Chavda, S. Gujarat Univ., India

I.M. Las Das, Banar as Hindu Univ., India

S. Cuperman, Tel A viv Univ., Israel

E. Greenspan, Nuc. Res. Center, Israel

P. R osenau, Israel Inst. of Tech., Israel

Int'l. Center for Theo. Physics, Trieste, Italy

I. Kawakami, Nihon Univer sity, Japan

T. Nakayama, Ritsum eikan Univ., Japan

S. Nagao, Tohoku Univ., Japan

J.I. Sakai, Toyama Uni v., Japan

S. Tjotta, Univ. I Bergen, Norway

M.A. Hellberg, Univ. of $\mathrm{Natal}$, South Africa

H. Wilhelms on, Chalmers Univ. of Tech., Sweden

Astro. Inst., Sonnenborgh Obs., The Netherlands

T. J. Boyd, Univ. College of North wales

K. Hubner, Univ. Heidel berg, W.Germany

H. J. Kaeppeler, Univ. of Stuttgart, West Germany

K. H. Spats chek, Univ. Essen, West Germany

\section{EXPERIMENTAL ENGINEERING}

B. Grek, Univ. du Quebec, Canada

P. Lukac, Komenskeho Univ., Czechoslovakia

G. Horikoshi, Nat'l Lab for High Energy Physics, Tsukuba-Gun, Japan

\section{EXPERIMENTAL}

F. J. Paoloni, Univ. of Wollongong, Australia

J. Kist emaker, Fom Inst. for A tomic

\& Molec. Physics, The Netherlands

\section{THEORETICAL}

F. Verheest, Inst. Vor Theo. Mech., Bel gi um

J. Teichmann, Univ. of Montreal, Canada

T. Kahan, Univ. Paris VII, France

R. K. Chhajlani, India

S. K. Trehan, Panjab Univ., India

T. Namikawa, Osaka City Univ., Japan

H. Nar umi, Univ. of Hiroshima, Japan

Korea A tomic Energy Res. Inst., Korea

E. T. Karlson, Uppsal a Uni v., Sweden

L. Stenflo, Univ. of UMEA, Sweden

J. R. Sar af, New Univ., United Kingdom 